\title{
A!
}

This is an electronic reprint of the original article.

This reprint may differ from the original in pagination and typographic detail.

Skrobo, Benedikt; Rolfes, Julian D.; Deska, Jan

\section{Enzymatic approaches for the preparation of optically active non-centrochiral compounds}

\section{Published in:}

Tetrahedron

DOI:

10.1016/j.tet.2016.01.026

Published: 10/03/2016

Document Version

Peer reviewed version

Please cite the original version:

Skrobo, B., Rolfes, J. D., \& Deska, J. (2016). Enzymatic approaches for the preparation of optically active noncentrochiral compounds. Tetrahedron, 72(10), 1257-1275. https://doi.org/10.1016/j.tet.2016.01.026

This material is protected by copyright and other intellectual property rights, and duplication or sale of all or part of any of the repository collections is not permitted, except that material may be duplicated by you for your research use or educational purposes in electronic or print form. You must obtain permission for any other use. Electronic or print copies may not be offered, whether for sale or otherwise to anyone who is not an authorised user. 


\title{
Enzymatic Approaches for the Preparation of Optically Active Non-Centrochiral Compounds
}

\author{
Benedikt Skrobo, Julian D. Rolfes and Jan Deska* \\ Department of Chemistry, Aalto-yliopisto, FI-02150 Espoo, Finland
}

\section{ARTICLE INFO}

\section{Article history:}

Received

Received in revised form

Accepted

Available online

\section{Keywords: \\ Biocatalysis \\ Axial Chirality \\ Planar Chirality \\ Helicity}

Stereochemistry

\section{Contents}

1. Introduction

2. Lipases and esterases as catalysts

2.1 Axial chirality

2.2 Helical chirality

2.3 Planar chirality

3. Oxidoreductases as catalysts

3.1 Axial chirality

3.2 Planar chirality

4. Miscellaneous biocatalytic systems

5. Conclusion

\section{Introduction}

Central chirality is ubiquitously found in molecular architectures and the basics of asymmetrically tetrasubstituted carbon atoms are a vital part in every first year organic chemistry undergraduate course. However, in addition to that a variety of other stereochemical elements are widespread both in the macrosopic world and on the molecular level. Despite the lack of appropriately decorated tetrahedral units, numerous structural features can lead to non-superimposable sets of enantiomeric molecules. On one side, inherent chirality can occur when free rotation is hindered due to steric or electronic constraints and the energy barrier for the interconversion of individual conformers prohibits rapid epimerization. The requirement for such an

\footnotetext{
* Corresponding author. E-mail address: jan.deska@aalto.fi (J. Deska)
}

atropisomerism is for example met in certain biaryls, ${ }^{1}$ overcrowded olefins, ${ }^{2}$ anilides ${ }^{3}$ and other helically twisted molecules. Moreover, non-central stereogenicity is observed when a suitable set of substituents at formally planar structural subunits opens up a spatial arrangement to allow for molecules to exist as image and mirror image. This broader term of static inherent chirality covers axially chiral allenes ${ }^{4}$ and alkylidenecycloalkanes as well as planar chiral cyclophanes, ${ }^{5}$ metallocenes, ${ }^{6}$ and calixarenes, ${ }^{7}$ among others.

Although not always self-evident at first glance and sometimes accompanied by a touch of chemical esotericism, all these aspects of chirality are not just artificial constructs but can be rather widely found in Nature, in the screw sense of biological macromolecules and likewise on the small-molecule level. Hence, a great number of structurally intriguing natural products 
featuring non-central chirality have been discovered over the years (Fig. 1). ${ }^{8,9}$ Not uncommonly, these secondary metabolites exhibit interesting pharmacological activity. As expected for molecules interacting in a biological environment, the sense of chirality plays a crucial role in this regard and particularly in the development and understanding of drugs, effects arising from elements of axial or planar stereogenicity must not be overlooked. ${ }^{10,11}$

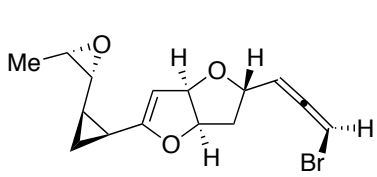

1, Okamurallene

2, Murrastifoline-F
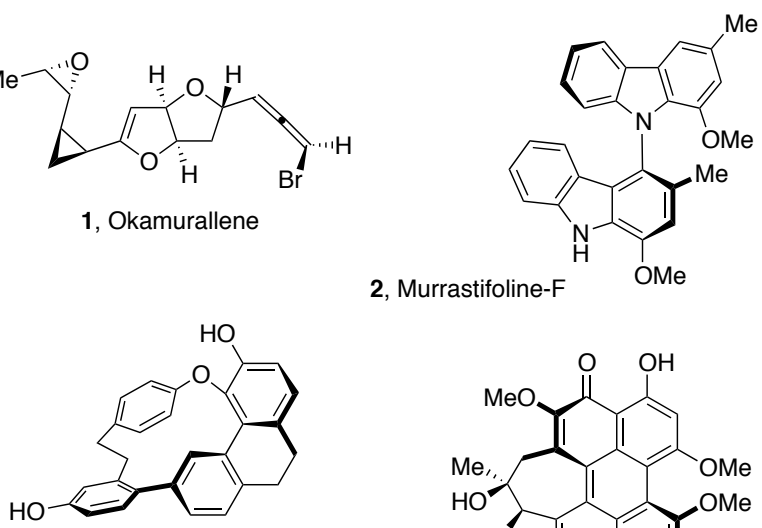

3, Cavicularin

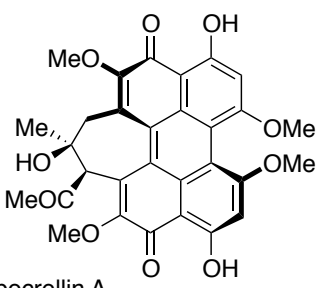

4, Hypocrellin A

Figure 1. Elements of non-central chirality in natural products.

A maybe even greater impact of axially, helically or planar chiral entities can be noted in the field of asymmetric catalysis. Nowadays, many of the privileged ligand systems found in stereoselective transition metal catalysis take advantage of the excellent properties of axially chiral binaphthyl core structure as controlling element. ${ }^{12,13}$ Likewise, with the appearance of ferrocenyl-based ligand families, inherently chiral organometallic phosphines started to play a major role in transition metal catalysis not only in academia but also in the industrial process design (Figure 2, top). ${ }^{14,15}$ In the same way, the relatively young

a) privileged ligands featuring non-central chirality

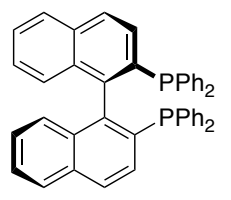

5, (R)-BINAP

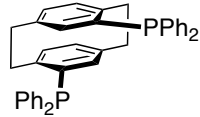

7, $\left(R_{\mathrm{P}}\right)$-Phanephos

b) benchmark organocatalysts based on non-centrochiral architecture<smiles>O=P(O)(O)Oc1c(Br)cc2ccccc2c1-c1c(Br)cc2ccccc2c1Br</smiles>

8, $(R)$-TRIP $\left(\mathrm{Ar}=2,4,6-\mathrm{Pr}_{3} \mathrm{Ph}\right)$

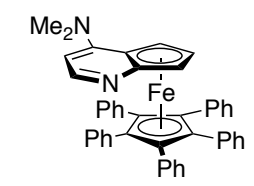

10, ferrocene-DMAP-hybrid

Figure 2. Features of axial and planar chirality in benchmark systems of modern organo- and transition metal catalysis. and booming area of organocatalysis is heavily relying on noncentrochiral architectures with some of the most prominent and successful catalytic systems being based on the atropisomeric binaphthyl backbone (Fig 2, bottom). ${ }^{16,17,18}$

In response to the growing demand for non-racemic, noncentrochiral building blocks, in the past decades the development of synthetic methods towards axially, helically, and planar chiral molecules in optically active form has attracted attention from various disciplines within organic chemistry. Here, also biocatalysis - with its broad variety of catalytic systems, excellent stereodiscrimination, and mild reaction conditions ${ }^{19,20}$ has been recognized as indispensable tool and found application for the synthesis of many structural families featuring these nonclassical chirogenicity elements. While the biocatalytic synthesis of smaller selections of non-centrochiral enantioenriched molecules has been covered to some extent as part of recent reviews, ${ }^{21,22,23}$ this report provides a full summary over all activites in the field over the past four decades. Introducing the basic activation modes of the most frequently employed enzyme classes, this review will highlight the power of biocatalysis ranging from classical whole-cell systems to highly contemporary tailor-made proteins - to effectively act on highly non-natural substrate structures in a synthetic fashion.

\section{Lipases and esterases as catalysts}

Among the many classes and subclasses of natural catalysts, the family of hydrolases has had by far most impact in the field of synthetic chemistry. In particular, enzymes catalyzing interconversions of carboxylic acid derivatives (esterases, lipases, proteases) have gained credence within the organic community over the years and are nowadays widely accepted as full-fledged synthetic tool. Natively located at the interface between aqueous and hydrophobic phases, the very high tolerance of lipases against organic solvents represents one important factor for their success. Although at first glance, ester hydrolysis is perhaps not regarded as synthetically challenging or exceedingly valuable transformation, the extraordinarily wide substrate scope together with a rather promiscuous interpretation of their catalytic role expanding to transesterifications, perhydrolysis, aminolysis et cetera - is turning the lipase/esterase enzymes into a very powerful class of catalysts. ${ }^{24}$ The majority of hydrolases employed in preparative organic chemistry belongs to the serine hydrolase superfamily. The common feature comprises a catalytic triad containing a nucleophilic serine that is typically activated through a proton shuffle involving adjacent histidine and aspartate moieties. As depicted for the catalytic transesterification (Scheme 1), the hydrogen-bonding arrangement within the triad substantially increases the serine's nucleophilicity, enabling attack of the hydroxy group at the ester substrate. The $\mathrm{Ser}_{105}$-bound first tetrahedral intermediate is further stabilized by hydrogen bond-donors $\left(\mathrm{Gln}_{106}, \mathrm{Thr}_{40}\right)$ forming the oxyanion hole. Elimination of alcohol R'OH leads to the formation of an acyl-enzyme complex that is subsequently attacked by external nucleophiles (here: $\mathrm{R} " \mathrm{OH}$ ), resulting in a second tetrahedral intermediate. With the liberation of a new ester the catalytic cycle is terminated. From these considerations it becomes apparent that enantiodiscrimination is potentially taking place both in the formation as well as in the decomposition of the acyl-enzyme complex, thus allowing for stereoselective transformations (resolution or desymmetrization) involving either (pro)chiral carboxylate derivatives or (pro)chiral nucleophiles. 


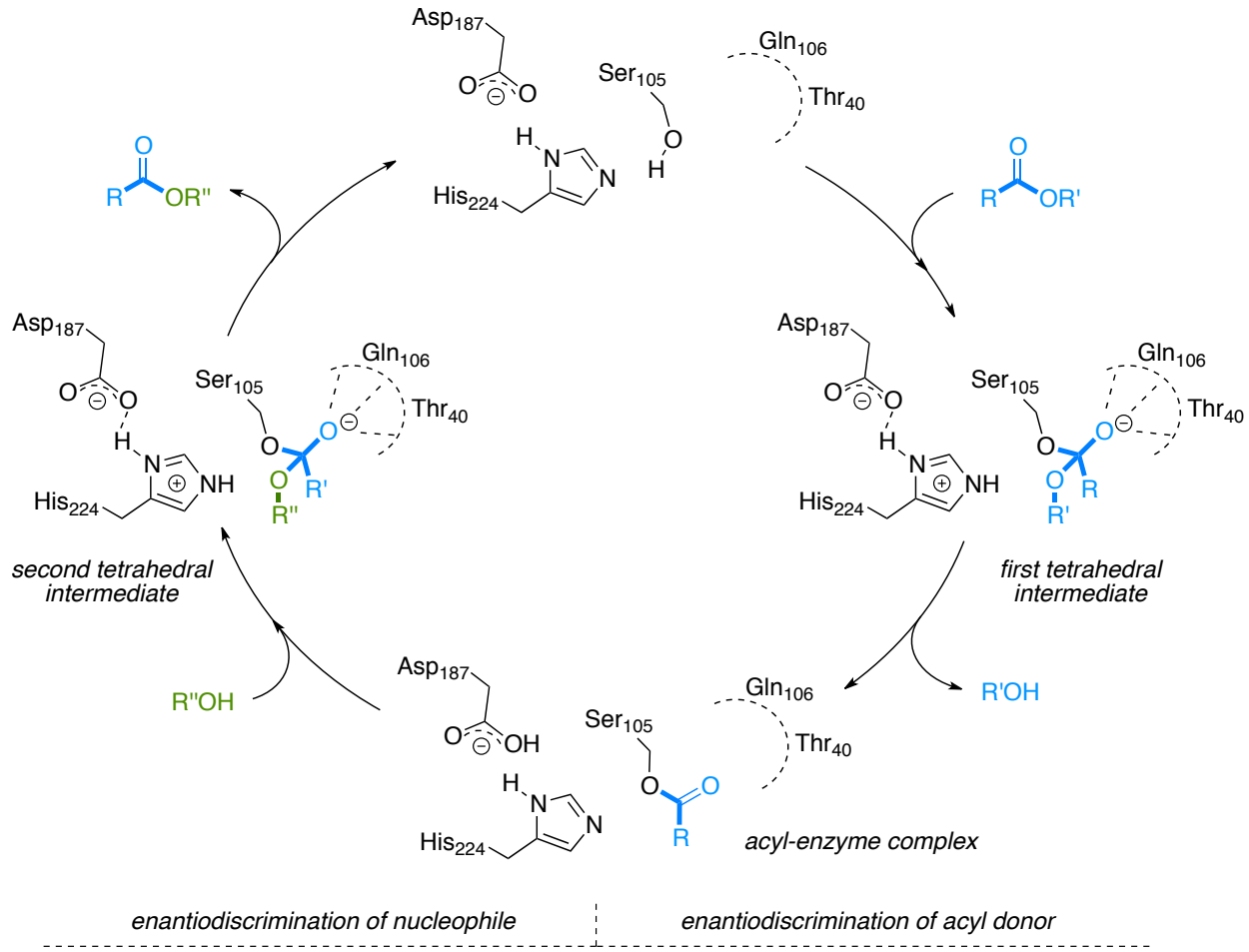

Scheme 1. Catalytic cycle of serine hydrolase-mediated transesterification (here: lipase B from Candida antarctica). ${ }^{25}$

\subsection{Axial chirality}

Two classes of compounds bearing axial chirality, allenes and biaryls, stand out with regard to their synthetic potential and thus also with the intensity they have been studied in the context of biocatalytic transformations (vide infra). Occasionally, also other structural entities attracted interest as potential substrates such as functionalized spiro[n.n]alkanes, with Fecht's acid as their most prominent representative. The group of Naemura reported on attempts to both desymmetrize and kinetically resolve various spiro[3.3] heptanes by means of esterases and lipases (Scheme $2)^{26,27}$ As part of their studies, Fecht's acid $(R)-\mathbf{1 2}$ was obtained by hydrolytic kinetic resolution from the racemic diester 11 using lipase from $C$. cylindracea in good yield, however, with a maximum

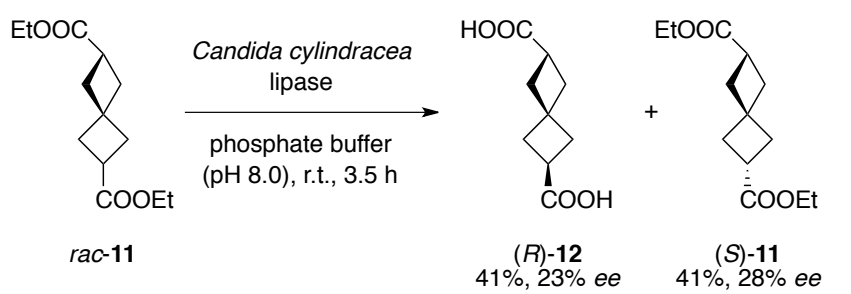

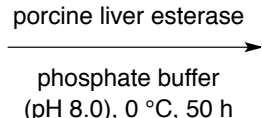

$(\mathrm{pH} 8.0), 0^{\circ} \mathrm{C}, 50 \mathrm{~h}$

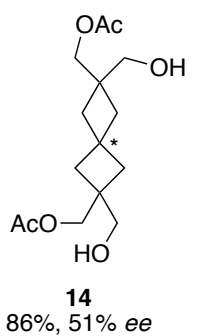

Scheme 2. Kinetic resolution and desymmetrization of spiro[3.3] heptanes. * Absolute configuration not assigned.

enantiomeric excess of $23 \%$. Other Fecht acid-derived alcohols were surveyed and desymmetrizative hydrolysis of tetraacetate 13 employing pig liver esterase yielded selectively the $\mathrm{C}_{2 \mathrm{v}^{-}}$ symmetric diacetate $\mathbf{1 4}$ in $51 \%$ ee.

Combining central and axial chirality, spiro[4.4]nonane-1,6diols were also included in these studies. While attempts to resolve the trans,trans-epimer of $\mathbf{1 6}$ suffered from mediocre enantioselectivity $\left(k_{\mathrm{rel}} \leq 11\right),{ }^{27}$ transesterification of $\mathrm{cis}$, cis-diol 16 by vinyl acetate with the aid of lipase P (from Pseudomonas sp.) led to highly optically enriched monoacetate $\mathbf{1 7}$ alongside with the nearly enantiopure starting material $16\left(k_{\text {rel }}>200\right)$ in excellent yields (Scheme 3 ). ${ }^{28}$ As the racemic diol was obtained by diastereoselective reduction of the axially chiral diketone rac15, simple reoxidation of the resolved 16 would potentially allow for the preparation of $(R)-\mathbf{1 5}$ exhibiting pure axial chirality.<smiles>OC1CCCC12CCCC2O</smiles>

rac-cis,cis-16 $\mathrm{Li}_{n \mathrm{BBu}^{+}{ }^{\mathrm{A}} \mathrm{I}^{\prime}{ }^{\prime \mathrm{Bu}} \mathrm{H}}^{\mathrm{Bu}}$<smiles>O=C1CCCC12CCCC2=O</smiles>

rac-15

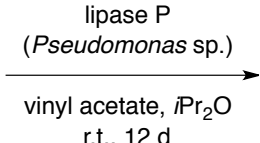

r.t., $12 \mathrm{~d}$

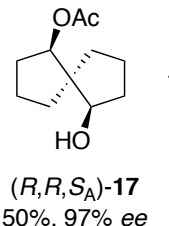

$50 \%, 97 \%$ ee<smiles>OC1CCCC12CCCC2O</smiles>

$\left(S, S, R_{\mathrm{A}}\right)-16$

[O]<smiles>CCCCC1(CC)CCCC1=O</smiles>

$(R)-15$ $46 \%, 97 \%$ ee

Scheme 3. Kinetic resolution of cis, cis-spiro[4.4]nonan-1,6-diol.

Geometrically related to Fecht's acid, allenic carboxylates have been studied in more detail over the years. In a first report 
by Jones et al. in $1986,{ }^{29}$ pig liver esterase was used as biocatalyst to resolve a series of tri- and tetrasubstituted allenic methyl esters with moderate to good enantioselectivities ( $k_{\text {rel }}$ up to 35), whereas higher substituted esters generally yielded better selectivities. The groups of Pietzsch and Hopf further improved this approach by optimizing reaction parameters and implementing additives (acetone and Triton X-100) to finally achieve a faster and more selective $\left(k_{\text {rel }}=60\right)$ preparative protocol (Scheme 4). ${ }^{30}$

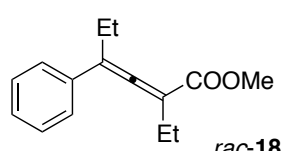
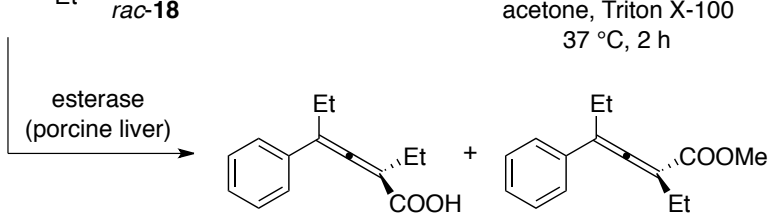

Jones:
Pietzsch:
$(R)-19$

Jones' conditions: phosphate buffer $(\mathrm{pH} 7.0)$

$$
\text { r.t., } 48 \mathrm{~h}
$$

Pietzsch's conditions: phosphate buffer ( $\mathrm{pH} 7.4)$ acetone, Triton $\mathrm{X}-100$ $37^{\circ} \mathrm{C}, 2 \mathrm{~h}$

$$
17 \%, 93 \% \text { ee }
$$$$
40 \%, 83 \% \text { ee }
$$

$79 \%, 22 \%$ ee $41 \%, 96 \%$ ee
Scheme 4. Enzymatic resolution of allenic esters by means of pig liver esterase.

While Jones' investigations revealed that a good degree of enantiodiscrimination by the esterase was evident for arylsubstituted allenes, substrates bearing aliphatic substituents suffered from very low enantioselectivity in the hydrolytic kinetic resolution. As this issue could not be sorted out by means of any other wild-type enzyme, the groups of Reetz and Bäckvall exploited mutagenesis in order to provide more selective biocatalysts. ${ }^{31}$ Directed evolution of lipase from Pseudomonas aeruginosa by means of the combinatorial active site saturation test method $^{32}$ resulted in a number of promising variant enzymes, the best of them resulting from a single mutation (Leu162Phe). Hydrolytic resolution of para-nitrophenyl ester $\mathbf{2 0}$ using this variant yielded the axially chiral acid (+)-21 in high optical purity, translating into an increase of enantioselectivity from 8.5 (wild-type-PAL) to 111 (PAL-L162F) (Scheme 5). In addition, hydrolysis by the Leu162Gly-mutant resulted in inversion of selectivity, however at a low level of enantiodiscrimination $\left(k_{\mathrm{rel}}=\right.$ 1.6).

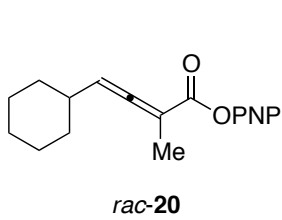

rac-20 lipase from

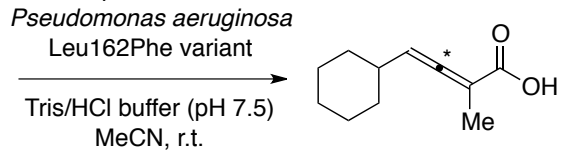

$(+)-21$

$44 \%, 96 \%$ ee
Scheme 5. Highly enantioselective kinetic resolution of cyclohexylallene carboxylate using a variant of $P$. aeruginosa lipase. * Absolute configuration not assigned.

Besides allenic carboxylic esters in particular allenols have made their way into the focus of stereochemical studies involving enzyme catalysis. In an early example, Gil et al. explored the potential of lipase MY (from Candida rugosa) as mediator for the enantioselective esterification (Scheme 6). ${ }^{33}$ Using lauric acid as acyl donor under non-aqueous conditions, good activity was observed for a number of primary allenic alcohols. However, stereoselectivities turned out mediocre at best and even inconsistencies in the general enantiopreference were noted $((S)$ selective for 22c vs. $(R)$-selective for $\mathbf{2 2 d}$ ).

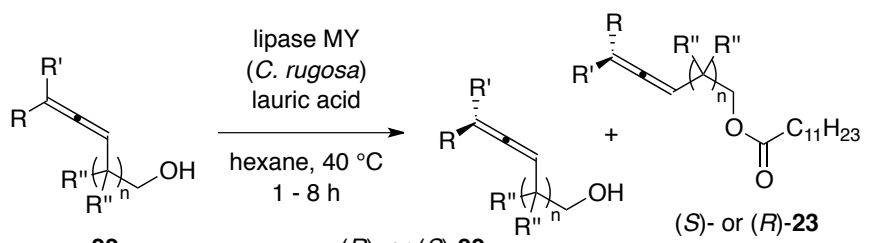

rac-22 $(R)$ - or $(S)-22$

$(S)$ - or $(R)-23$

$(R)-22 \mathrm{a}$
$80 \%, 10 \%$ ee<smiles>CCC(C)=CC(C)(C)CO</smiles>

$(R)-22 \mathrm{c}$
$25 \%, 20 \%$

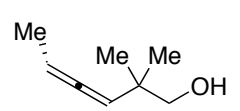

(S)-22d
Scheme 6. Esterification of allenic primary alcohols by lipase MY.

Later, studies on Gil's allenols by Cipiciani and coworkers confirmed the lack of high enantioselectivity for the C. rugosacatalyzed acylative resolution. On the other hand, they also showed that hydrolytic kinetic resolution of allenyl acetate rac$\mathbf{2 4}$ with lipase from $C$. rugosa (pre-treated with isopropanol) at low temperature $\left(4^{\circ} \mathrm{C}\right)$ in a biphasic reaction mixture (aqueous phosphate buffer ( $\mathrm{pH} 7.4) / n$-hexane) proved to be much more selective $\left(k_{\text {rel }}=110\right)$ yielding allenic alcohol $(R)$-22d in very high optical purity (Scheme 7). ${ }^{34}$

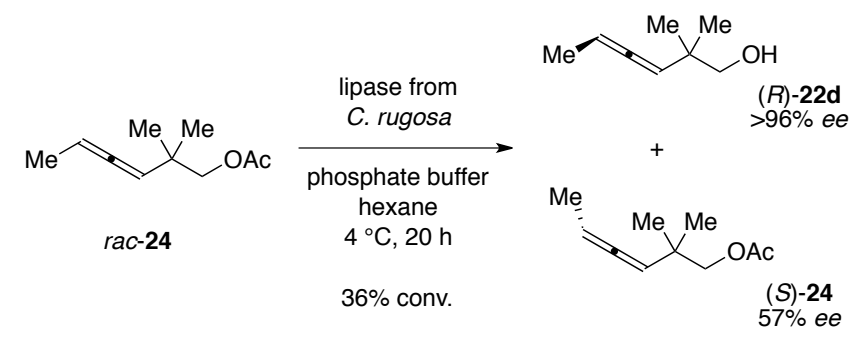

Scheme 7. Hydrolytic kinetic resolution of allenyl acetates.

Since the extent of enantiodiscrimination in enzymatic processes can most often be attributed to steric effects, the enantioselective bioconversion of methyl-terminated allenes appears, despite Cipiciani's success, a rather ambitious undertaking. As shown by Zemlicka et al. sterically more encumbered terminating groups at the cumulenes allow for clean and stereoselective biocatalytic transformations with high optical purities for both the starting material and the resolved product. Thus, a large-scale synthesis of the anti-HIV effective $(R)$ cytallene (26) was developed based on a lipase-catalyzed acylative kinetic resolution (Scheme 8). ${ }^{35}$ After treatment of racemic $N^{4}$-benzoylcytallene $\mathbf{2 5}$ with vinyl butyrate and lipase AK in THF, the optically enriched alcohol and butyrate were separated by column chromatography. Global deprotection of either of the compounds gave rise to $(R)$ - or $(S)$-cytallene, respectively, in high yield and enantiomeric excess greater $95 \%$. 
<smiles>O=C(Nc1ccn(C=CCO)c(=O)n1)c1ccccc1</smiles>

rac-25

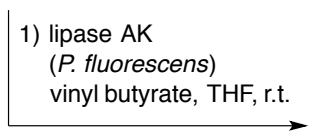

2) separation

3) $\mathrm{NH}_{3}, \mathrm{MeOH}$<smiles>Nc1ccn(C=CCO)c(=O)n1</smiles><smiles>Nc1ccn(C=CCCO)c(=O)n1</smiles>

(S) -26

$40 \%>95 \%$ ee

Scheme 8. Chemoenzymatic preparation of optically enriched antiviral cytallene.

An in-depth study regarding the influence of substituents in the acylative kinetic resolution of allenic primary alcohols was presented by the group of Bäckvall. Lipase from porcine pancreas was identified as promising biocatalyst for the preparation of enantiomerically enriched allenic compounds and its synthetic potential could be illustrated with realization of a chemoenzymatic approach towards striatisporolide $\mathrm{A}^{36}$ In particular, aryl-substituted allenols were resolved with very high enantioselectivity $\left(k_{\text {rel }}>100\right)$ whereas olefinic and aliphatic terminal groups caused a substantial decrease in selectivity (Scheme 9).

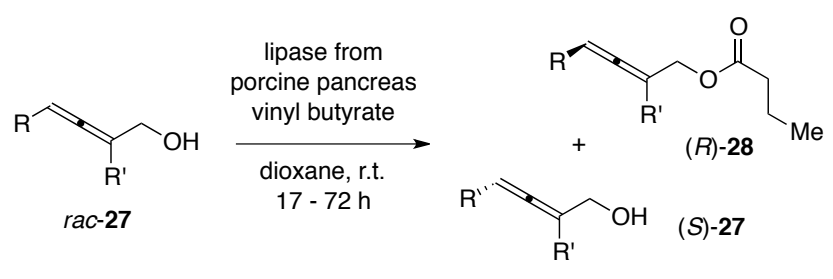

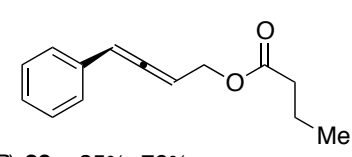

(R)-28a, 25\%, 76\% ee $\left(k_{\mathrm{rel}}=9\right)$<smiles>CCCC(=O)OCC(=Cc1ccccc1)CC</smiles>

(R)-28c, 39\%, 97\% ee $\left(k_{\text {rel }}=127\right)$<smiles>C=C(C)C=C=C(C)COC(=O)CCC</smiles>

$(R)-\mathbf{2 8 e}, 30 \%, 81 \%$ ee $\left(k_{\text {rel }}=13\right)$

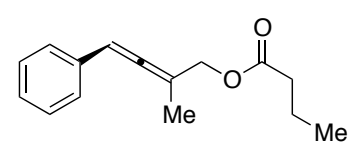

(R)-28b, $42 \%, 98 \%$ ee $\left(k_{\text {rel }}>200\right)$<smiles>CCCC(=O)OCC(C)=C=Cc1ccc(Cl)cc1</smiles>

(R)-28d, 49\%, 97\% ee $\left(k_{\text {rel }}>200\right)$<smiles>[CH2-]CCC(=O)OCC(C)=C=CCCCCC</smiles>

(R)-28f, 59\%, 68\% ee $\left(k_{\text {rel }}=23\right)$

Scheme 9. Enzymatic resolution of primary allenols by porcine pancreatic lipase.

Regardless of the extent of enantioselectivities, kinetic resolutions always suffer from one general disadvantage that is the limitation of the maximum theoretical yield of $50 \%$ for the

desired enantiomer. For centrochiral compounds, a wellestablished approach to cope with this intrinsic constraint, known as dynamic kinetic resolution (DKR), deals with the combination of resolution processes and chemical or thermal racemization of the starting material. Exploiting palladium bromide complexes bearing $N$-heterocyclic carbene ligands as catalyst for the selective racemization of axially chiral allenic alcohols, ${ }^{37}$ Bäckvall et al. also managed to perform resolutions based on the previously described system in a dynamic fashion leading to optically enriched allenic butyrates in high yield and enantiomeric excesses up to $89 \%$ (Scheme 10). ${ }^{38}$

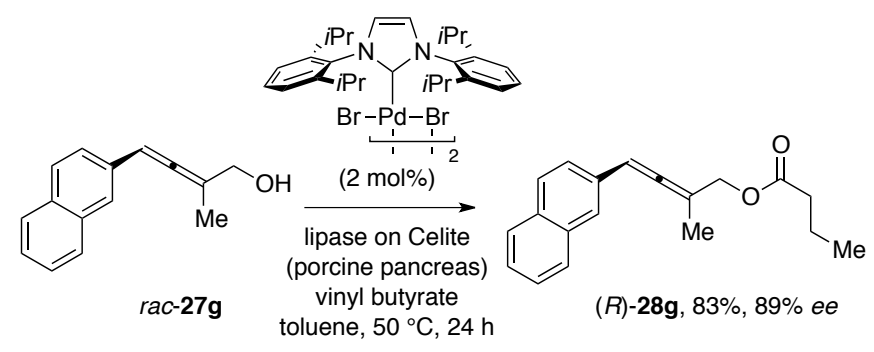

Scheme 10. Dynamic kinetic resolution of allenols based on the combination of lipase and palladium catalysis.

A conceptual different approach to avoid yield limitations was presented by Deska and coworkers introducing structurally related prochiral allenic diols as nucleophilic substrate for enzymatic transesterifications. ${ }^{39}$ Here, selective acylation of one of the enantiotopic hydroxy groups by porcine pancreatic lipase as sole catalyst allows for the preparation of enantiopure allenic alcohols in very high yields (Scheme 11). Similarly to the kinetic resolution by means of lipase from porcine pancreas, arylsubstituted allenes distinguished themselves as excellent substrates for this transformation. However, as an intrinsic feature of desymmetrizations, even for less well recognized diols subsequent kinetic resolution of the thus formed monobutyrate allowed for the preparation of highly enantioenriched axially chiral allenes such as $\mathbf{3 0 f}$.
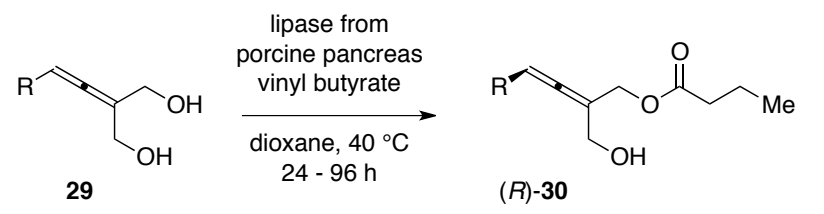

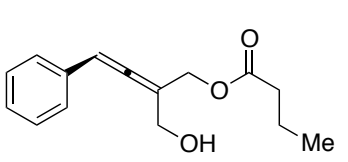

(R)-30a, 95\%, 98\% ee<smiles>CCCC(=O)OCC(=Cc1ccc(Cl)cc1)CO</smiles>

(R)-30c, 93\%, 99\% ee<smiles>CCCC(=O)OCC(=C=Cc1cccc(C)c1)CO</smiles>

(R)-30b, $90 \%, 98 \%$ ee<smiles>CCCCCCCC=C=C(CO)COC(=O)CCC(C)C</smiles>

(R)-30e, $89 \%$, 99\% ee<smiles>CCCC(=O)OCC(=C=Cc1ccc2ccccc2c1)CO</smiles>

(R)-30d, 93\%, 99\% ee

Scheme 11. Enantioselective desymmetrization of allenic diols. 
The desymmetrization approach, in particular in combination with subsequent allene cyclizing transformations proved to be useful in the synthesis of optically active $O$-heterocycles as recently demonstrated in the total synthesis of the norlignanes hyperione $\mathrm{A}$ and $\mathrm{B} .{ }^{40}$ Moreover, the substrate scope of the method was expanded by implementing another biocatalyst, lipase from Pseudomonas fluorescens, that showed high selectivity in the enantioselective acylation of tetrasubstituted allenic diols (Scheme 12). ${ }^{41}$

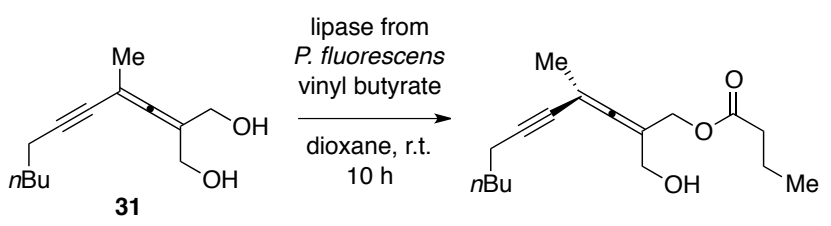

7 more examples: $74-98 \%$ ee

(R)-32, 93\%, 99\% ee

Scheme 12. Tetrasubstituted allenes as substrates in the lipasecatalyzed enantioselective acylation.

Pseudomonas fluorescens lipase also proved to be effective in the stereodiscrimination of allene-related axially chiral cyclobutylidenemethanols. ${ }^{42}$ Fiaud et al. described a protocol using succinic anhydride as acylating agent that allowed for a simple purification of the non-reactive enantiomer by removal of the enzymatically formed succinic monoester through basic extraction. Although enantioselectivities remained rather poor both for the 3-tert-butyl-substituted cyclobutane $33\left(k_{\text {rel }}=4\right)$ as well as for the related phenyl-substituted derivative $\left(k_{\text {rel }}=1.5\right),(-$ )-33 could be obtained in $89 \%$ ee after pushing the resolution to high conversion (Scheme 13).

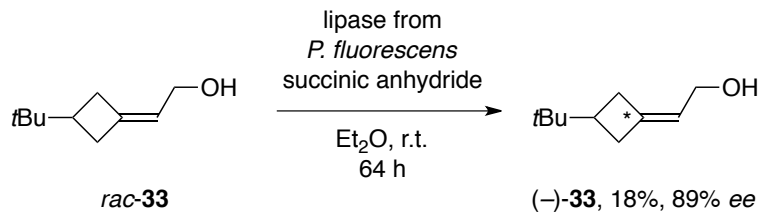

Scheme 13. Kinetic resolution of axially chiral cyclobutylidenemethanols. * Absolute configuration not assigned.

Atropisomeric biaryls are representing the second major class of compounds examined in the context of biotransformations related to axial chirality. Here, particularly BINOL (35, 1,1'-bi-2naphthol) and its derivatives, being important precursors of all kinds of biaryl architectures, have been in the focus of the initial studies on enzyme-mediated processes. In 1985, Ikekawa and coworkers reported on the first biotransformation involving atropisomeric BINOL derivatives. ${ }^{43}$ While the use of isolated hydrolases such as pig liver esterase in the selective hydrolysis of BINOL-diesters failed due to low activity, the whole cell fermentation of the dipentanoate $\mathbf{3 4}$ employing the Bacillus strain L-75 led to a very effective kinetic resolution with high optical purities of both the BINOL 35 and the remaining diester $\left(k_{\text {rel }}=\right.$ 174)(Scheme 14). Interestingly, an inverted enantiopreference was observed in the hydrolysis of the corresponding diacetate, however, at substantially lower enantioselectivity $\left(k_{\mathrm{rel}}=4.3\right)$.

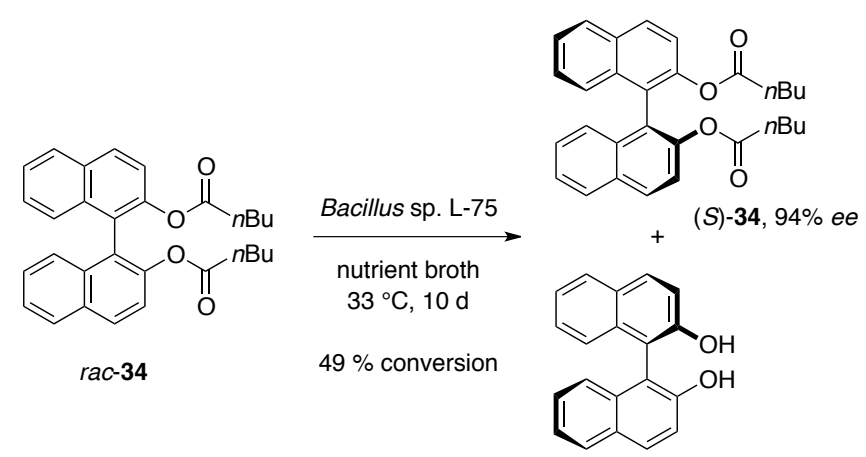

$(R)-35,96 \%$ ee

Scheme 14. Whole cell resolution of BINOL-dipentanoate.

In 1989, Kazlauskas found that cholesterol esterase (both from porcine and bovine sources) was capable to catalyze the selective hydrolysis of BINOL-dipentanoate as well. Using a biphasic $\mathrm{Et}_{2} \mathrm{O} /$ phosphate buffer system in combination with the isolated enzyme, highly $(S)$-selective hydrolysis $\left(k_{\mathrm{rel}}>200\right)$ was achieved. ${ }^{44}$ Important from a practical perspective, also crude bovine pancreas acetone powder could be used as biocatalysts offering a cheap and scalable method for the multi-gram scale preparation of optically pure BINOL. ${ }^{45}$ Later, Kazlauskas' method has been adapted by Blakemore et al. for the preparation of related 8,8'-biquinolinols (Scheme 15). ${ }^{46}$

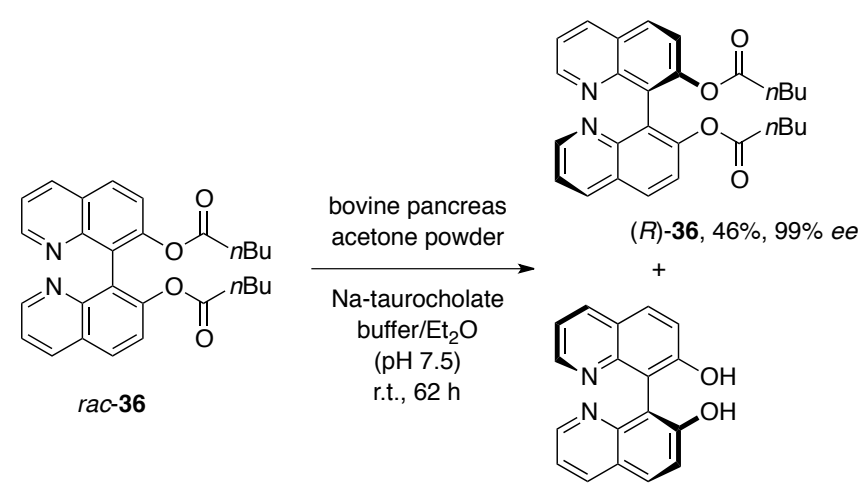

(S) $-37,37 \%, 77 \%$ ee

Scheme 15. Kinetic resolution of 'aza-BINOLs' by crude pancreas acetone powder.

Both Miyano et $a l^{47}$ and Lin et al. ${ }^{48}$ showed that also pancreatic lipase is able to accept BINOL-derived substrates and discriminate between the two atropisomeric forms of BINOLdiesters. In a double kinetic resolution employing racemic 1indanol (39) as nucleophile for the biocatalytic transesterification high optical purities of all four major components were achieved (Scheme 16). Nonetheless, considering the fact that both pancreatin and crude pancreas acetone powder gave rise to a similar reaction outcome and selectivity as in the case of cholesterol esterase, here the involvement of impurities often found in crude lipase formulations should not be disregarded entirely. ${ }^{49}$ 
<smiles>CC(C)C(=O)Oc1ccc2ccccc2c1-c1c(OC(=O)C(C)C)ccc2ccccc12</smiles>

rac-38

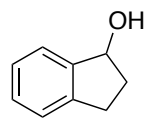

$\operatorname{rac}-39(2 \mathrm{eq})$ lipase from
porcine pancreas

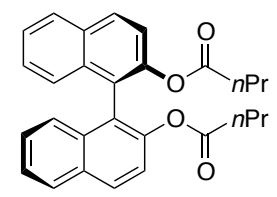

(R)-38, $46 \%, 98 \%$ ee

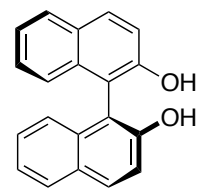

(S)-35, 46\%, 98\% ee

Scheme 16. Double kinetic resolution of BINOL-dibutyrate and indanol.

In non-aqueous media, BINOL derivatives cannot only serve as acyl donor but in the same way can act as nucleophiles for enzymatic transesterifications. In 1989, Oda and coworkers presented a protocol for the kinetic resolution of BINOL by lipase-catalyzed acylation. Also here, the chain length of the ester moiety played a crucial role and best results were obtained with vinyl butyrate in a mixture of diisopropyl ether and acetone $\left(k_{\mathrm{rel}}=\right.$ $47){ }^{50}$ Despite the use of an excess of the acyl donor only formation of the BINOL-butyrate $(R)-\mathbf{4 1}$ was observed and the monoester could be isolated in good enantiomeric purity $(91 \%$ $e e$ )(Scheme 17). Oda's procedure was later successfully expanded to $6,6^{\prime}$-disubstituted BINOLs by Holland et al. ${ }^{51}$

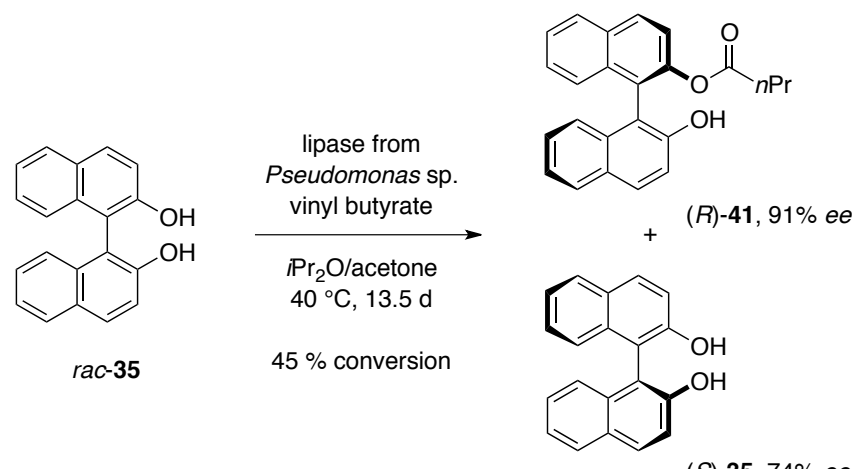

(S)-35, $74 \%$ ee

Scheme 17. Kinetic resolution of BINOL by lipase-catalyzed monoacylation.

A number of related, differently decorated or truncated $C_{2^{-}}$ symmetric biaryls have also found application as substrates in lipase-catalyzed transformations. Aiming for the resolution of simple biphenyl systems, the groups of Sanfilippo and Delugo reported on the enzymatic esterification of 6,6'-dimethoxy-2,2'biphenol (Scheme 18). High selectivities were achieved in the monoacylation of rac-42 with a strong influence of the lipase's immobilization being noted. ${ }^{52}$ Using lipase from Pseudomonas cepacia, diatomaceous earth proved to be an optimal support $\left(k_{\mathrm{rel}}\right.$ $>200$; nowadays commercialized as PS-IM) whereas the protein in non-immobilized form or on other mineralic materials lacked either activity or selectivity.

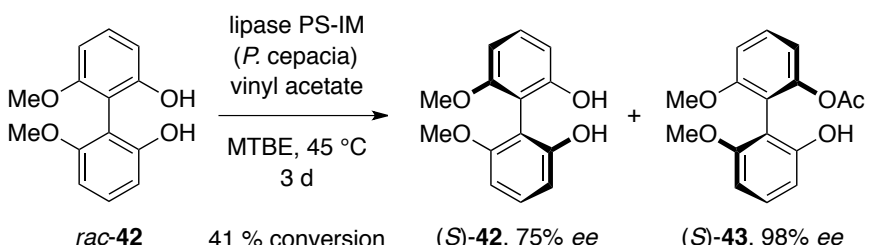

Scheme 18. Biocatalytic resolution of 6,6'-dimethoxy-2,2'biphenol.

The group of Seki used primary alcohol groups instead of the phenolic hydroxy moieties as handle for lipase-mediated esterifications. In addition to a good accessibility and high reactivity of these nucleophilic groups, they can serve as surrogate for other functional units. Seki et al. succeeded in identifying two enantiocomplementary lipases, from Serratia marcescens and Humicola sp., that opened up routes to both enantiomeric diols $\mathbf{4 4}$ in optically pure form via acylative kinetic resolution using vinyl hexanoate. Subsequent oxidation employing manganese dioxide gave rise to the axially chiral aldehyde (45) that could be further oxidized to the corresponding dicarboxylic acid (46) without loss of enantiopurity (Scheme 19). ${ }^{53}$

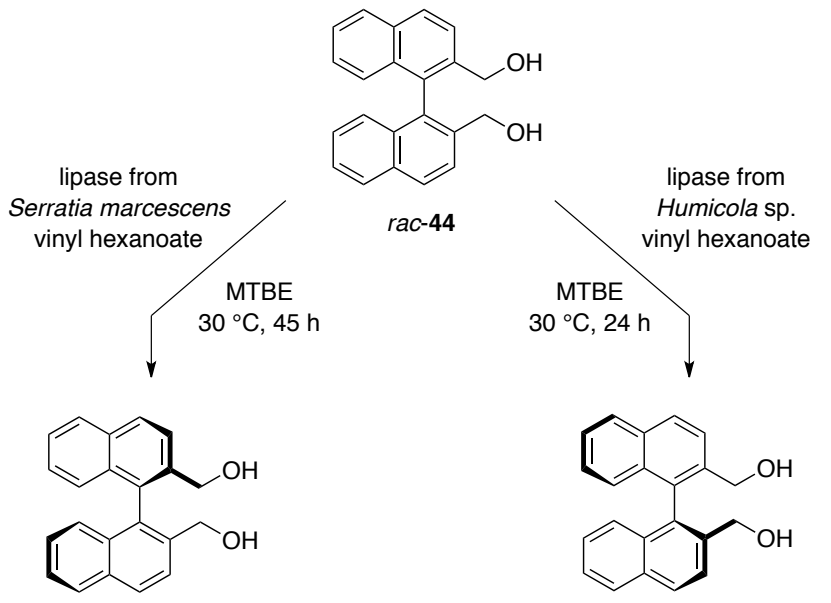

(R)-44, 41\%, 99\% ee

(S)-44, 45\%, 99\% ee
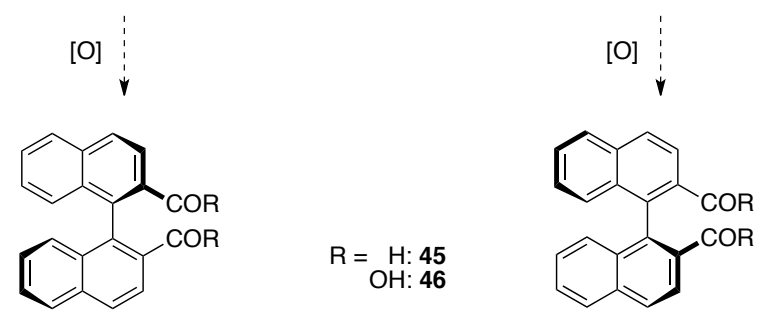

$(R)-45$ or $(R)-46$

(S)-45 or (S)-46

Scheme 19. Synthesis of alcohol-, aldehyde- and carboxylatefunctionalized binaphthyls via acylative kinetic resolution. 
In a similar fashion, Sanfilippo and coworkers were able to synthesize axially chiral pyridine- $N$-oxides through enzymatic acetylation. $^{54}$ Using a bis-(hydroxymethyl)-substituted bipyridine- $\mathrm{N}$-oxide (47) in combination with Lipozyme (Mucor miehei lipase) and vinyl acetate, the optically pure starting material could be recovered after $24 \mathrm{~h}$, however, an exhaustive overacylation was required due to a relatively low enantioselectivity of the enzyme catalyst (Scheme 20).<smiles>[O-][n+]1cccc(CO)c1-c1c(CO)ccc[n+]1[O-]</smiles>

rac-47

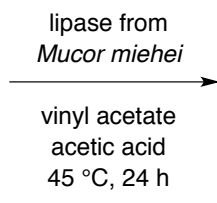

$85 \%$ conversion

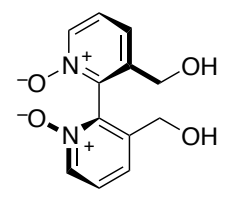

(R)-47, 15\%, 99\% ee
Scheme 20. Resolution of an atropisomeric bpy- $N$-oxide.

A more remote functional handle was described by Seki et al. during their synthesis of binaphthyl-based axially chiral ketones, ${ }^{55}$ that can serve as catalysts in asymmetric epoxidations. ${ }^{56}$ As a convenient alternative to a lengthy synthesis of the organocatalyst from enantioenriched 1,1'-binaphthyl-2,2'dicarboxylic acid, the direct resolution of the corresponding glycerol-derived bis-lactone by biocatalytic deacylation of $\mathrm{rac}-\mathbf{4 8}$ at the glycerol's 2-position was investigated (Scheme 21). Both the basic binaphthyl as well as the 3,3'-dichloro derivative were resolved in very high enantioselectivity $\left(k_{\text {rel }}(\mathbf{4 8 a})\right.$ : $>200, k_{\text {rel }}(48 b)$ : $85)$ giving rise to the enantiomerically pure alcohols that upon oxidation delivered the desired organocatalysts.

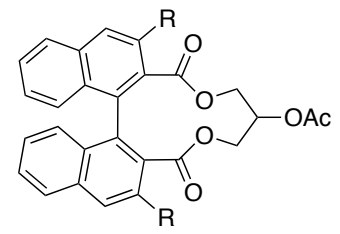

$\mathrm{Cl}:$ rac-48b

\begin{tabular}{c|c} 
lipoprotein lipase & $\begin{array}{c}\text { TRIS buffer }(\mathrm{pH} 7.5) \\
\text { toluene } \\
\text { (Pseudomonas sp.) }\end{array}$ \\
$30^{\circ} \mathrm{C}, 48 \mathrm{~h}$
\end{tabular}

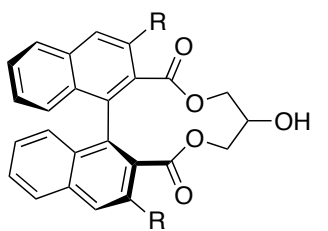

(R)-49a, $46 \%, 99 \%$ ee (R)-49b, $45 \%$, $99 \%$ ee

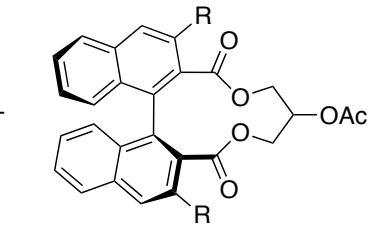

(S) $-48,50 \%, 99 \%$ ee (S) $-48,52 \%, 93 \%$ ee
Scheme 21. Biocatalytic selective hydrolysis of axially chiral mixed triglycerides.

Recognition of the stereochemical information cannot only be achieved involving functional groups attached to the biaryls' 2,2'positions. The group of Fuji demonstrated a kinetic resolution of binaphthyls through enzymatic alcoholytic deacylation of 3,3'diacetoxy-O,O'-dimethyl-BINOL (50) (Scheme 22).$^{57}$ Despite an apparently mediocre enantioselectivity $\left(k_{\mathrm{rel}}=12\right)$, the enantiomerically pure monoacetate $(S)$-51 could be obtained after repeated recrystallization (from $79 \%$ ee to $99 \% e e$ ).
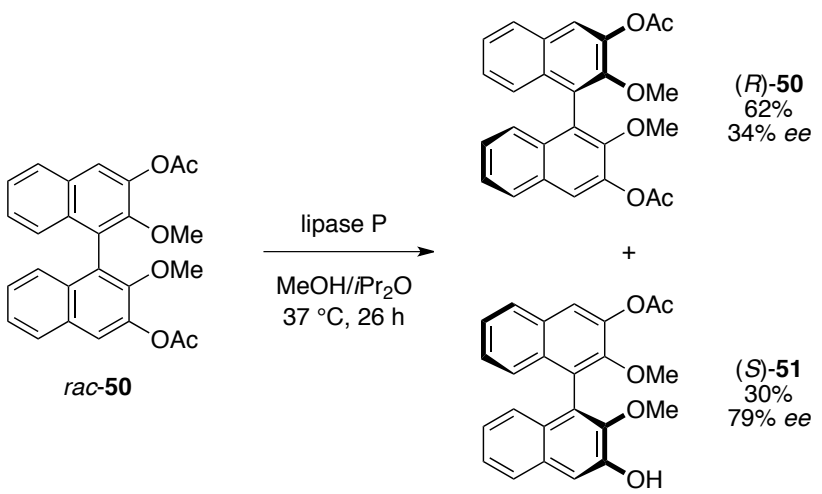

Scheme 22. Kinetic resolution of a 3,3'-disubstitued BINOLdiether.

A low enantioselectivity was observed by Sanfilippo, Delogo et al. in initial attempts on the alcoholytic kinetic resolution of diacetyl thioesters of rac-52 with $P$. cepacia lipase, among others $\left(k_{\text {rel }} \leq 5\right)$. In response to this, they designed an elegant workaround exploiting a dynamic kinetic asymmetric transformation in the acetylative resolution of the parent dithiol rac-52 (Scheme 23). Using vinyl acetate as not only as acetyl donor but at the same time as source for acetaldehyde, upon initial activation by the lipase the formation of rapidly epimerizing hemithioacetals from $\mathbf{5 2}$ and the aldehyde was detected. Subsequent stereoselective esterification resulted in two diastereomeric bis-acetates (53) that, after chromatographic separation and hydrolysis, delivered both enantiomers of the starting material in good optical purity. ${ }^{58}$

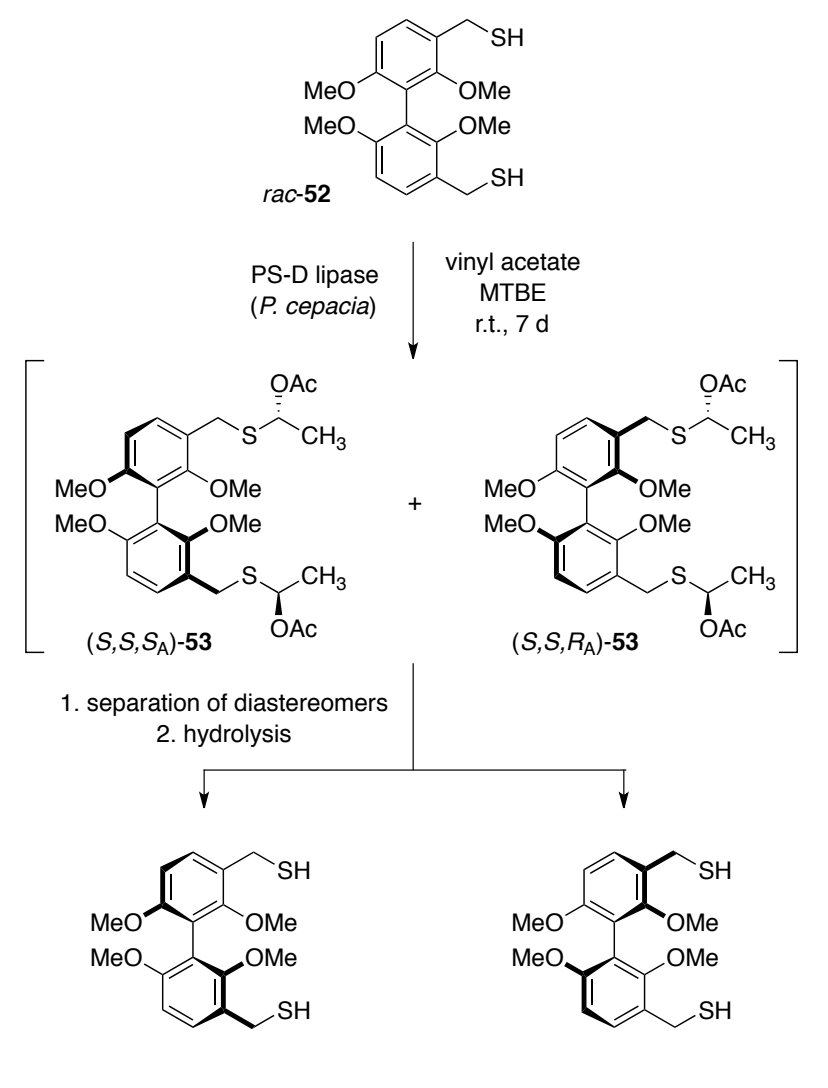

(S)-52, 30\%, 96\% ee

(R)-52, 32\%, 91\% ee

Scheme 23. Dynamic kinetic asymmetric transformation via remote acetylation as key step in the enantiomeric separation of biaryl 52. 
In addition to the well-studied $C_{2}$-symmetric biaryl structures, a number of non-symmetric atropisomeric binaphthyls have been examined as potential substrates for lipase-catalyzed asymmetric transformations. Here, Aoyagi and coworkers investigated the biocatalytic amidation of racemic binaphthyl-based carboxylic esters. ${ }^{59}$ The direct attachment of the reactive carboxylate moiety to the biaryl core or connection via a single methylene unit resulted in ester building blocks that proved to be unsuitable for the lipase-catalyzed reactions ( $C$. antarctica lipases) due to a lack of activity. On the other hand 3-(binaphthyl)propionate rac-54 could be resolved by means of Chirazyme L-2 and 3aminopropionitrile as nucleophile. After substantial overacylation due to a modest selectivity $\left(k_{\text {rel }}=13\right)$ enantiomerically pure starting material could be recovered (Scheme 24). A similar observation in how subtle differences in chain length or binaphthyl decoration strongly affect the reaction outcome was later also reported by Itoh et al. on a wider substrate spectrum. ${ }^{60}$

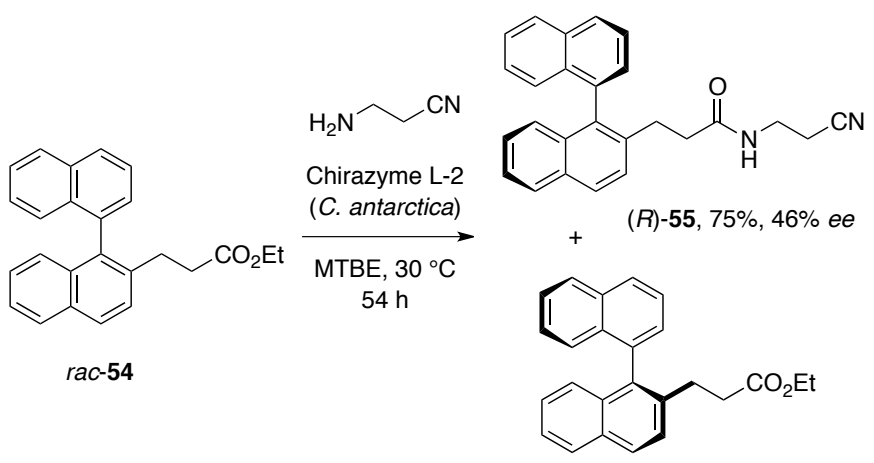

(S)-54, 21\%, 99\% ee

Scheme 24. Enzymatic enantioselective aminolysis.

By inversion of the reactivity pattern, thus employing axially chiral binaphthyl alkylamines as nucleophiles in combination with lipase from $P$. aeruginosa as most selective catalyst, improved relative rates were observed $\left(k_{\text {rel }}(\mathbf{5 6}): 45, k_{\text {rel }}(\mathbf{5 7})\right.$ : $>200$ ). This allowed for the preparation of optically enriched butyric amide products via enzymatic acylation (Scheme 25). ${ }^{61}$

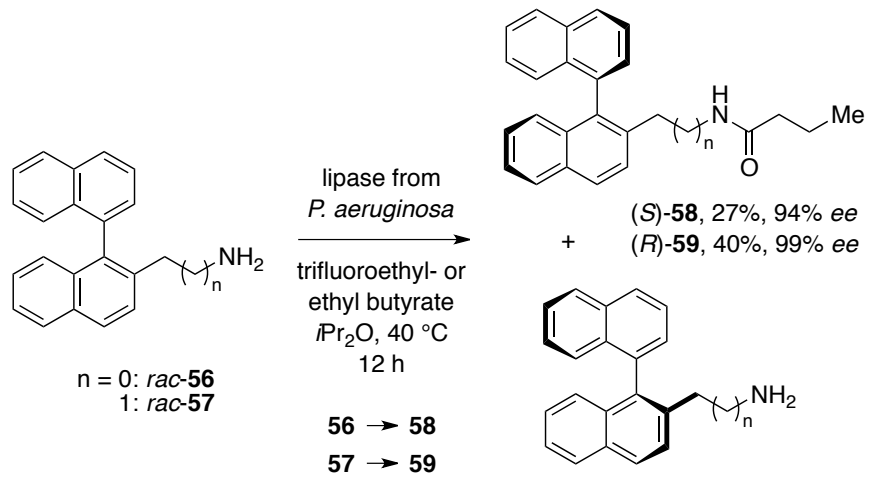

(R)-56, 63\%, 29\% ee (S) $-57,51 \%, 67 \%$ ee

Scheme 25. Kinetic resolution via lipase-catalyzed amidation.

The group of Aoyagi further investigated alternative nucleophilic handles for the biocatalytic resolution of binaphthyls. Both aldoximes and ketoximes as well as their corresponding $O$-acetyloximes showed good reactivity in lipasemediated (de)acetylation reactions. ${ }^{62,63}$ Also for the alcoholytic deacetylation of aldoxime $\mathbf{6 0}$, lipase from $P$. aeruginosa proved to be the enzyme of choice providing nearly enantiopure $(R)-60$ via kinetic resolution (Scheme 26).

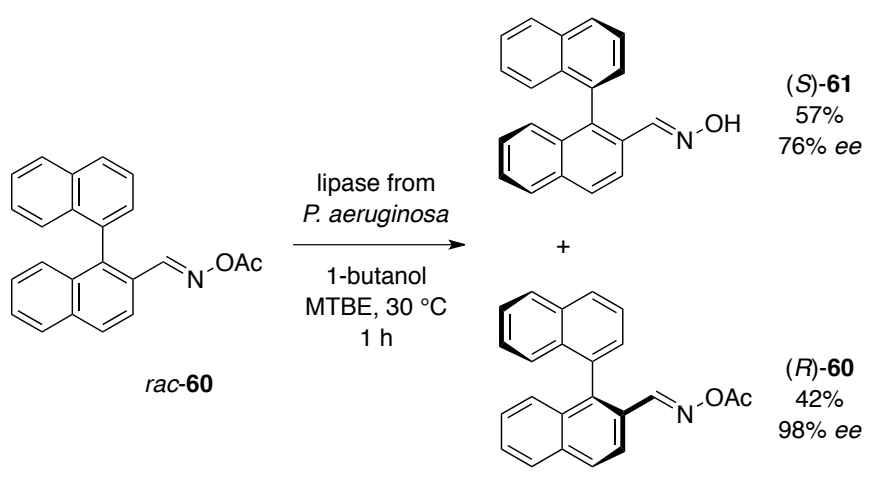

Scheme 26. Alcoholytic resolution of $O$-acetoxyimines.

The atroposelective ring-opening of lactone-bridged biaryls pioneered by Bringmann represents a particularly elegant approach towards non- $C_{2}$-symmetric optically active compounds without the yield limitations of classical kinetic resolutions. ${ }^{64}$ The principle relies on the fast epimerization of helically twisted lactones such as $\mathbf{6 2}$ that allows for dynamic kinetic resolutions via nucleophilic trapping reactions. However, as already discussed by Aoyagi, ${ }^{59}$ the attack by serine hydrolases on carboxylates directly attached to the biaryl core appears to proceed sluggishly. Thus, attempts to conduct Bringmann's lactone concept on the basis of a hydrolase-catalyzed alcoholytic or hydrolytic opening suffered from very low reactivity and only traces of the desired products $(\mathbf{6 3})$ were obtained (Scheme 27). ${ }^{65}$ In contrast, reduction of the biaryl lactone to the corresponding primary alcohol 64 provided a suitable substrate for a (nondynamic) kinetic resolution by Mucor miehei lipase with moderate enantioselectivity $\left(k_{\text {rel }}=7.8\right)$.

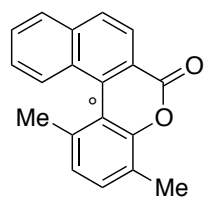

rac-62

(configurational labile)

$$
\mid \begin{gathered}
\mathrm{LiAlH}_{4} \\
\mathrm{THF}^{\circ} \\
0^{\circ} \mathrm{C}, 90 \mathrm{~min}
\end{gathered}
$$<smiles>Cc1ccc(C)c(-c2c(CO)ccc3ccccc23)c1O</smiles>

rac- $64,92 \%$

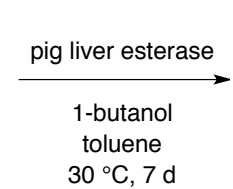

$30^{\circ} \mathrm{C}, 7 \mathrm{~d}$

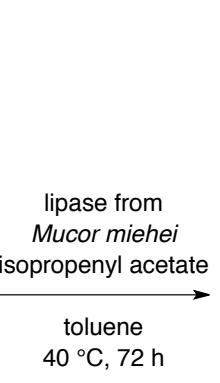

$63,6 \%, 13 \%$ ee

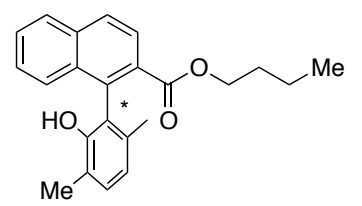

Scheme 27. Unproductive dynamic kinetic resolution of biaryl lactone 62. * Absolute configuration not assigned.

In 2002, Matsumoto and coworkers presented a successful desymmetrization protocol based on the enantioselective deacetylation of symmetrical 2,6-diacetoxybiaryls (65). ${ }^{66}$ The enantiotopos discrimination by lipases either from $P$. cepacia or $C$. antarctica proved to be very effective and a number of axially chiral, highly enantioenriched phenols could be produced by enzymatic hydrolysis in good to excellent yields well beyond the 
$50 \%$ threshold of the previously depicted resolution approaches (Scheme 28).

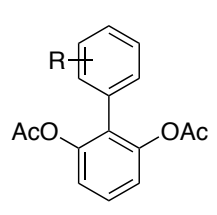

65

lipase from

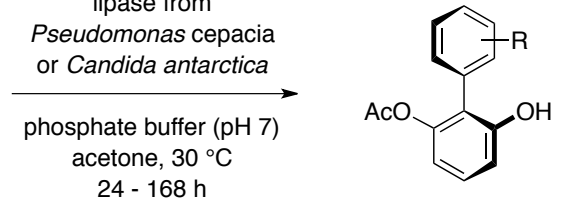

(R)-66

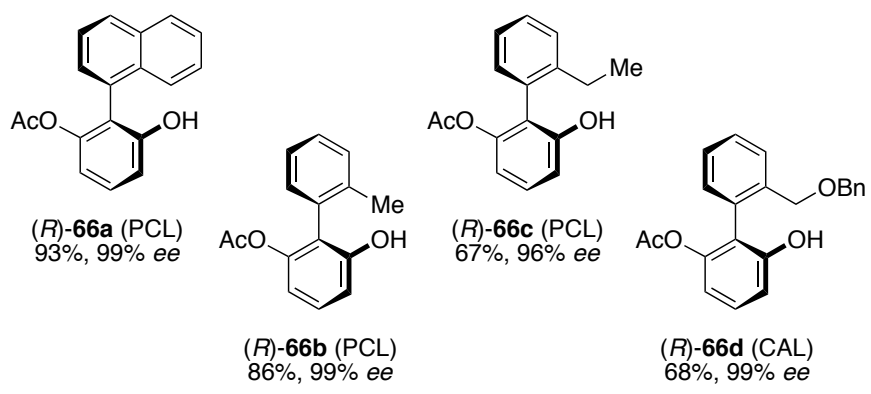

Scheme 28. Biocatalytic desymmetrization of 2,6-diacetoxybiaryls.

Structurally closely related to the binaphthyl family, also 1,1'spirobisindanes have been evaluated as potential enzyme substrates. Kazlauskas' system employing pancreas acetone powder as catalyst exhibited good activity also for the axially chiral spiro compound $\mathbf{6 7}$ and hydrolytic kinetic resolution of the dihexanoate yielded both optically active product diol $(R)-\mathbf{6 8}$ as well as the enantioenriched starting material in high enantiomeric excess, the latter being subsequently hydrolysed to give the enantiomeric diol (S)-68 (Scheme 29). ${ }^{44}$
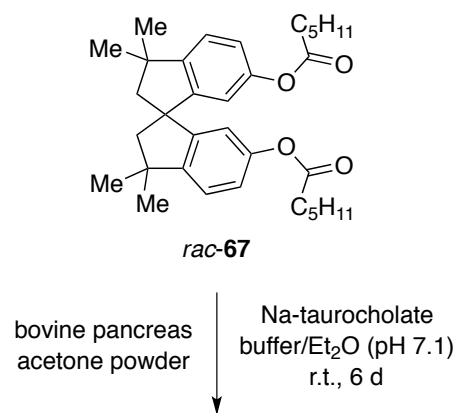

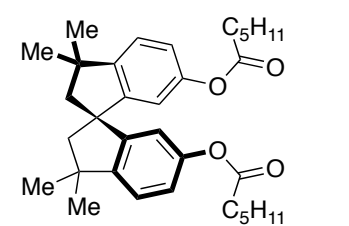

(S)-67, 40\%, 95\% ee (after hydrolysis)

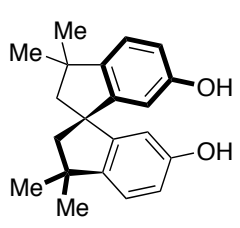

(R)-68, 55\%, 95\% ee

Scheme 29. Kinetic resolution of an axially chiral 1,1'spirobisindane. 


\subsection{Helical chirality}

Stereoisomerism can also be found in sterically overcrowded 1,1-diarylalkenes with reduced conformational mobility. ${ }^{67}$ Considering the rigidity of those systems, the term helical chirality is probably most suited for the description of the stereochemical properties. Helically twisted piperidines have been discussed as intermediates in the synthesis of the farnesyl protein transfer inhibitor SCH66336 and Morgan et al. reported on the enzymatic kinetic resolution of piperidine 69 and derivatives thereof. ${ }^{68}$ An extensive screening revealed that lipase from Pseudomonas aeruginosa provided best selectivities in the biocatalytic amidation with a subtle influence of the used acyl donor. Here, resolution of rac-69 by means of trifluoroethyl isobutyrate and the commercial lipase LIP-300 ( $P$. aeruginosa) gave rise to both enantiomers in excellent optical purity as the initially formed amide $\mathbf{7 0}$ could be easily hydrolyzed without loss of enantiomeric excess (Scheme 30).

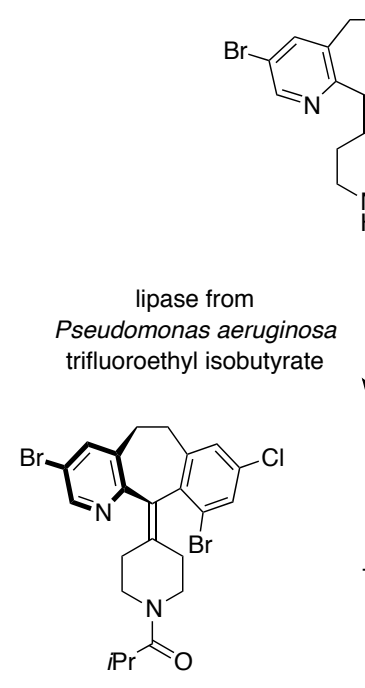

(P)-70, 97\% ee

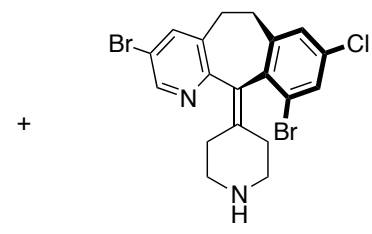

(M)-69, 96\% ee
Scheme 30. Enzymatic resolution of a helically twisted alkylidenepiperidine.

As part of their intensive studies on optically active helicenes, ${ }^{69}$ in 1990 Katz et al. reported the first enzymatic resolution of a [5]helicenetetraone-derived phenolic acetate. Again, Kazlauskas' procedure based on pancreatic acetone powder proved to be effective and able to recognize the helical screw sense in the twisted, central chiral rac-71. ${ }^{70}$ After separation of the products and oxidation by ceric ammonium nitrate, the purely helically chiral diquinones $(P)$ - and $(M)-\mathbf{7 3}$ were obtained in moderate enantiomeric purity (Scheme 31$)$.

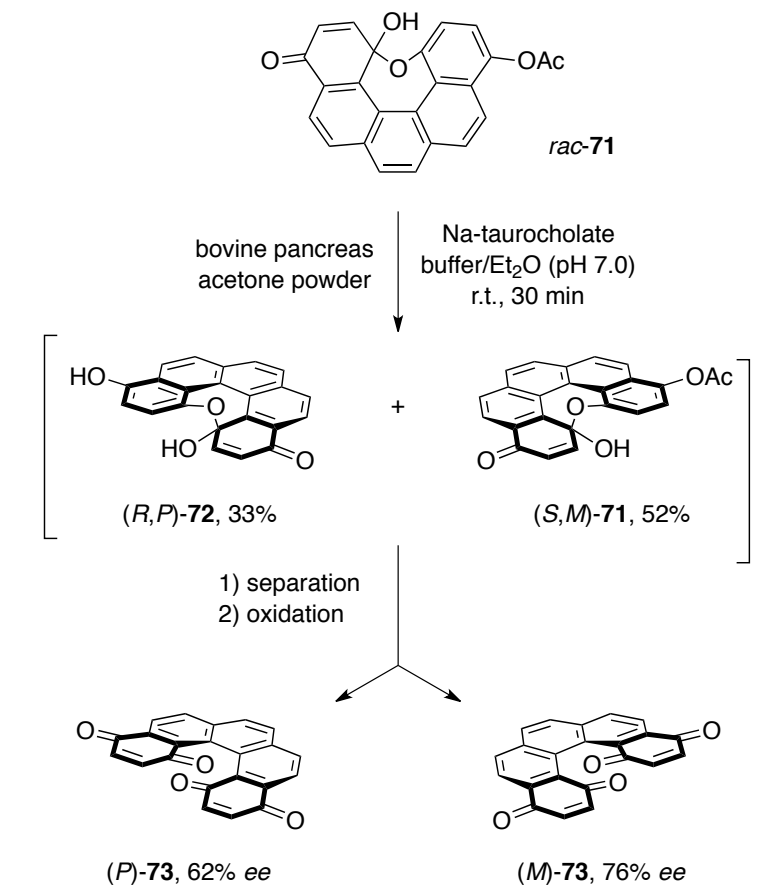

Scheme 31. Biocatalytic synthesis of enantioenriched [5]helicenetetraones.

The direct resolution of a full-fledged helicene was the target of studies by Tanaka, Nakamura and coworkers. ${ }^{71,72}$ Two enantiocomplementary lipases were identified to catalyze the selective acetylation of a hydroxymethyl-decorated tetrathia[7]helicene (74). A lipase formulation from $P$. cepacia converted preferentially the $(M)$-enantiomer $\left(k_{\text {rel }}=40\right)$ forming both mono- and diacetate products and allowing for the isolation of highly enantioenriched $(P)$-configured diol 74 (Scheme 32). Novozym 435 (lipase B from $C$. antarctica) on the other hand served as catalyst for the preparation of the corresponding $(M)$ $\operatorname{diol}\left(k_{\mathrm{rel}}=19\right)$.
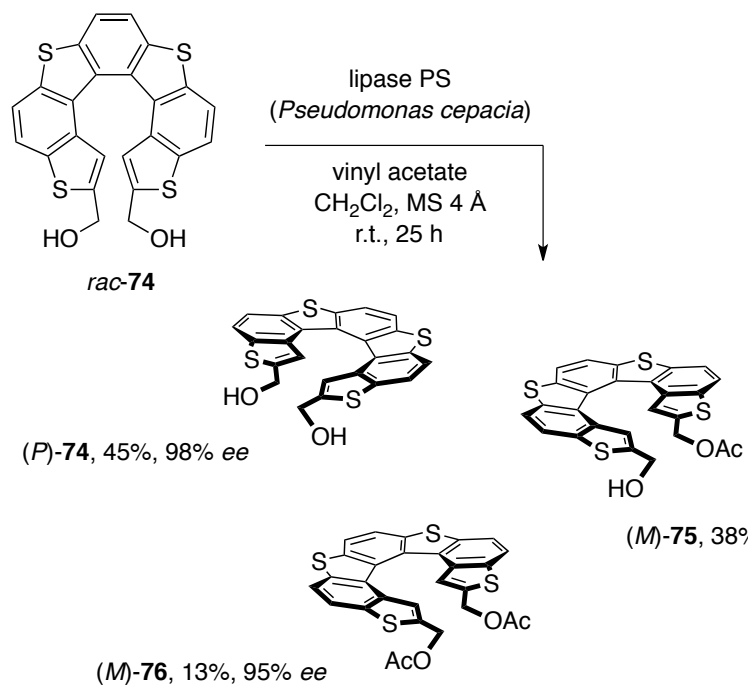

(M)-75, 38\%, 80\% ee

(M) $-\mathbf{7 6}, 13 \%, 95 \%$ ee

Scheme 32. Kinetic resolution of a twisted tetrathia[7]helicene. 


\subsection{Planar chirality}

Representing a privileged ligand structure, particularly ferrocene-based architectures have been studied in much detail with regard to enzymatic protocols to obtain planar-chiral enantioenriched material. A selection has also been covered as part of two recent reviews. ${ }^{73,74}$ In addition, iron and chromium carbonyl half-sandwich complexes as well as purely organic cyclophanes have found application as substrates in lipase- and esterase-mediated processes. In 1990, Yamazaki et al. reported on the first effective biocatalytic preparation of enantioenriched ferrocenes with planar chirality. ${ }^{75}$ With pig liver esterase as catalyst, the organometallic diester $\mathbf{7 7}$ was successfully hydrolyzed to yield the optically active monoester $\mathbf{7 8}$ as major product with moderate enantiomeric excess of $74 \%$ (Scheme 33). A number of other half- and full-sandwich complexes based on iron, manganese and chromium were included in their studies but proved to be unselective or unreactive under the tested condition. $^{75,76}$

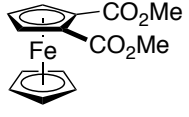

77

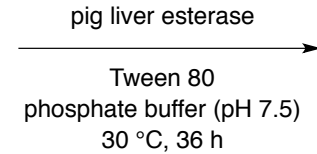

$30{ }^{\circ} \mathrm{C}, 36 \mathrm{~h}$

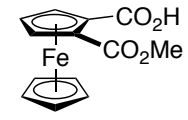

(S) $-\mathbf{7 8}, \mathbf{8 8} \%, 74 \%$ ee
Scheme 33. Enantioselective hydrolysis of ferrocene-diester 77.

Very high selectivities, on the other hand, were found by Jaouen, Howell et al. in the biocatalytic desymmetrization of meso-1,2-disubstituted arenechromium tricarbonyls exploiting more flexible methylene-extended ester groups. ${ }^{77}$ Treatment of symmetric 79 with pig liver esterase in water/methanol provided enantiopure monoester $\mathbf{8 0}$ in good yield (Scheme 34). The rather labile hydrolysis products were directly converted to their corresponding unsymmetric diesters by means of chemical esterification to give stable chromium complexes featuring planar chirality.<smiles>CCOC(=O)CCc1ccccc1C(C)(C)C=O</smiles>

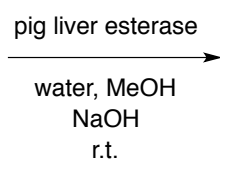

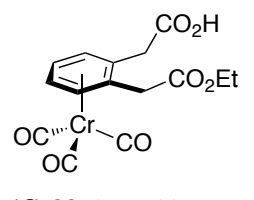

(S)-80, 85\%, 99\% ee
Scheme 34. Enzymatic desymmetrization of ester-decorated arenechromium tricarbonyls.

From 1992 on, Izumi and coworkers presented a series of different approaches utilizing biocatalysts for the resolution of functionalized ferrocenes. ${ }^{78}$ Initially, planar chiral organometallic enol acetates were employed as substrates for the enzymatic hydrolysis. Lipase PS (from $P$. cepacia) exhibited a certain selectivity on $\mathbf{8 1}\left(k_{\mathrm{rel}}=8\right)$ and after excessive hydrolysis under formation of the ferrocene ketone $\mathbf{8 2}$ as major product, enantiomerically pure $(S)-81$ could be isolated in $20 \%$ yield (Scheme 35).<smiles>CC(=O)OC1=CCCc2ccc(F)cc21</smiles>

rac-81

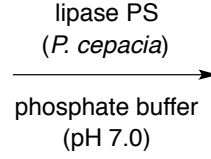

$(\mathrm{pH} 7.0)$
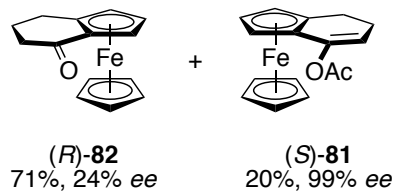

Scheme 35. Enantioselective hydrolysis of planar chiral enol acetates.
They also investigated the hydroysis and transesterification of related diastereomerically confined cis-[4] $(1,2)$ ferrocenophane acetates, butyrates and alcohols, respectively. ${ }^{78,79}$ Here, enzymatic deacylation by means of Candida rugosa lipase provided high enantioselectivities in the kinetic resolution of butyrate $\mathbf{8 2}$ that led to the isolation of both the product alcohol $(R, R)-\mathbf{8 3}$ as well as the remaining ester $(S, S)$-82 in good yields and high optical purity (Scheme 36).

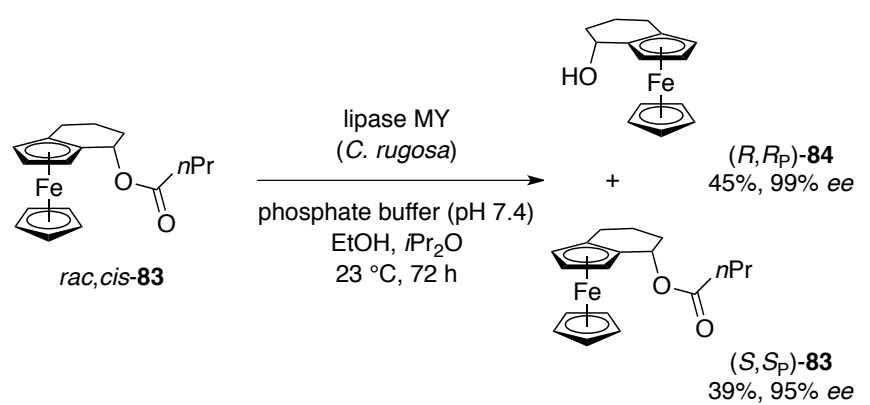

Scheme 36. Selective hydrolysis of ferrocenophane $\mathbf{8 2}$.

On the basis of Izumi's studies on simple 1,2-disubstituted ferrocene and ferrocenophane lipase substrates, ${ }^{80,81}$ the group of Nicolosi performed an in-depth investigation on the kinetic resolution of 2 -substituted ferrocenemethanols. ${ }^{82,83,84,85}$ In the enzyme-mediated acetylation, the lipases of Candida antarctica (type B) and Candida cylindracea, respectively, provided moderate to good enantioselectivities for a variety of halogen-, sulfide- and aminomethyl-functionalized ferrocenes (scheme 37). Later, Aribi-Zouioueche and Riant published further refinements of this method (e.g. for 85e) taking into account solvent and additive effects. 86,87
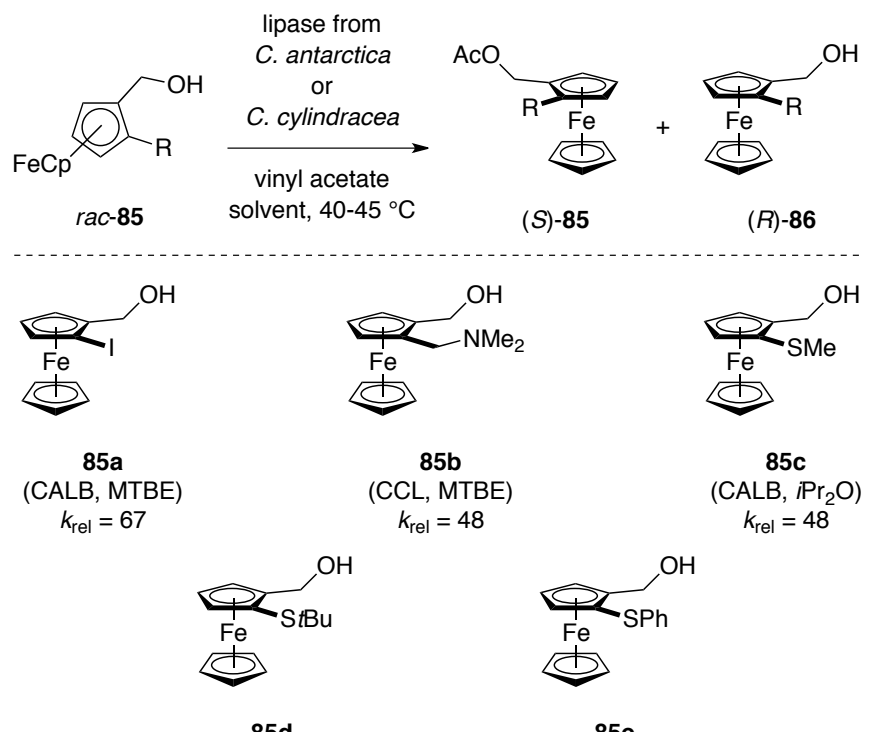

(CALB, $\left.\mathrm{Pr}_{2} \mathrm{O}\right)$

$k_{\text {rel }}=10$

(CALB, MTBE)

$k_{\text {rel }}=121$

Scheme 37. Kinetic resolution of functionalized ferrocenemethanols.

Rigby et al. presented a family of $\left(\eta^{6}-\right.$ cycloheptatriene)chromium complexes as substrates for lipasecatalyzed transesterifications. ${ }^{88}$ Depending on the position of the hydroxymethyl group at the planar cycloheptatriene unit, moderate to good enantioselectivities were observed in the acylative kinetic resolution. As exemplified in the resolution of 
the 3-hydroxymethyl derivative 87 (Scheme 38), treatment with lipase PS-30 in isopropenyl acetate led to enantioenriched, planar chiral acetate $(R)-\mathbf{8 8}$ alongside with optically active alcohol $(S)$ 87.

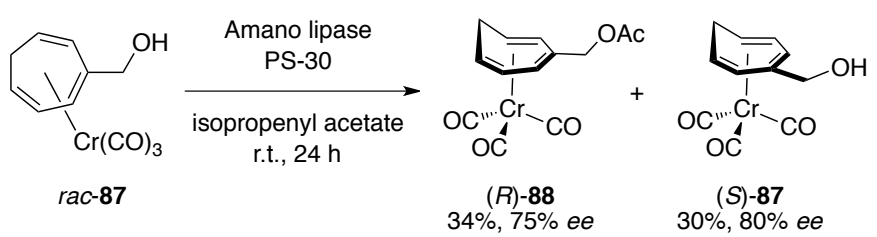

Scheme 38. Kinetic resolution of planar chiral $\left(\eta^{6}\right.$-cycloheptatriene)chromium carbonyls.

The groups of Crout, ${ }^{89}$ Howell and Jaouen ${ }^{90}$ investigated various $\left(\eta^{4}\right.$-butadiene)iron tricarbonyl structures and hydrolase handles for the preparation of enantioenriched organometallics. Crout $e t$ al. found that pig liver esterase efficiently mediated the hydrolysis of (2-ethoxycarbonylbutadiene)iron tricarbonyl 89 yielding both the remaining ester as well as the corresponding carboxylic acid product in good enantiomeric excess (Scheme 39).

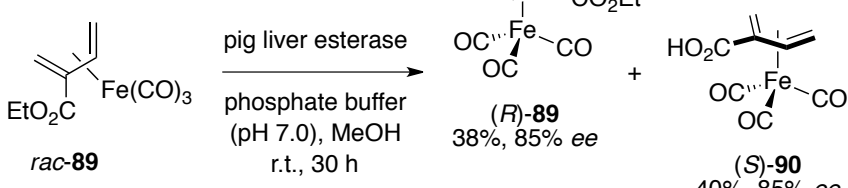

$$
\begin{aligned}
& 40 \%, 85 \% \text { ee }
\end{aligned}
$$

Scheme 39. Pig liver esterase as catalyst for the kinetic resolution of $\mathbf{8 9}$.

The direct attachment of a hydrolysable acetate group to the diene moiety opens up a route to a labile dienol complex that readily decomposes under liberation of carbon monoxide. Based on this behavior, Amslinger and Schmalz developed organometallic compounds for the enzyme-triggered CO-release in a cellular environment. ${ }^{91}$ Though aiming for biological responses and pharmaceutical effects, in vitro studies revealed that both pig liver esterase and lipase from Candida rugosa were able to recognize the planar chirality of the iron complexes. Hence, after esterase-catalyzed hydrolysis of $\mathbf{9 1}$, the non-reactive enantiomer could be re-isolated in optically pure form at high conversion (Scheme 40).

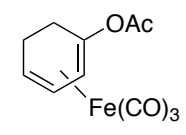

rac-91

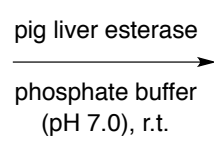

$210 \mathrm{~min}$

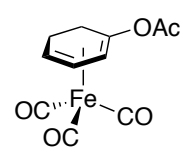

$91,{ }^{*} 20 \%, 99 \%$ ee
Scheme 40. Resolution of CO-releasing cyclohexadiene iron tricarbonyl. *Absolute configuration not determined, random enantiomer depicted.

While initial studies on the [2.2]paracyclophane backbone by Izumi and Hinata attempting hydrolytic and acylative resolutions of methylester- and hydroxymethyl-derivatives, respectively, suffered from very low selectivities, ${ }^{92}$ good optical purities were achieved by Braddock et al. using a $C_{2}$-symmetrical 4,12diacetoxy-[2.2]paracyclophane as lipase substrate. ${ }^{93}$ Deacylation of 92 by means of C. rugosa lipase in a biphasic toluene/water system gave rise to the remaining diacetate in $87 \%$ ee as well as to a mixture of mono- and diol, yielding enantioenriched pure (S)-93 after hydrolysis (Scheme 41).

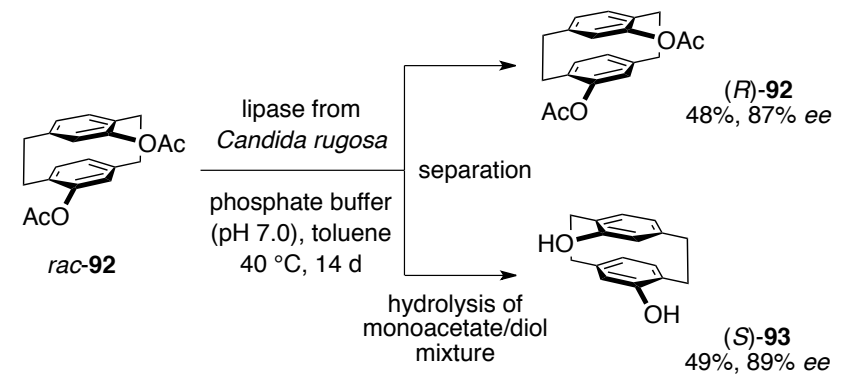

Scheme 41. Lipase-mediated resolution of $C_{2}$-symmetric diacetoxy-[2.2]paracyclophane $\mathbf{9 2}$.

Similarly, Pietzsch and coworkers reported that the same enzyme efficiently resolved monoacetoxy-[2.2]paracylophane 94. ${ }^{94,95}$ A crucial role was attributed to the cosolvent with diethyl ether allowing for enantioselectivities of $k_{\text {rel }}>100$ as opposed to e.g. toluene with $k_{\text {rel }}=20$. Under optimized conditions, both enantiomers were obtained with $\geq 90 \%$ enantiomeric excess (Scheme 42).

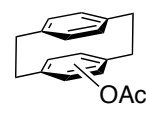

rac-94

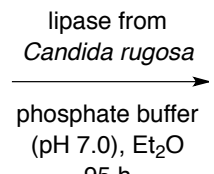

$95 \mathrm{~h}$

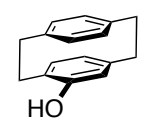

(R)-95 $51 \%, 90 \%$ ee

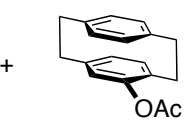

$(S)-94$
$4 \%, 99 \%$
Scheme 42. Kinetic resolution of acetoxycyclophane 93.

The structurally intriguing architecture of calix[4]arenes served as core structure for stereochemical studies by McKervey and coworkers. ${ }^{96}$ Exploiting lipase-mediated desymmetrizations, inherently chiral calix[4]arenes were obtained through selective acetylation of tris(hydroxyethyl)-decorated barrel-shaped substrates (96). Both Aspergillus niger lipase and Candida cylindracea lipase proved to be active on the para-unsubstituted 96b and gave rise to either of the enantiomeric products in good to excellent enantiomeric purity (Scheme 43), however, at relatively low yields.

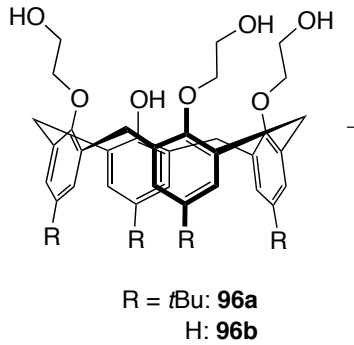

$\mathrm{H}:$ 96b
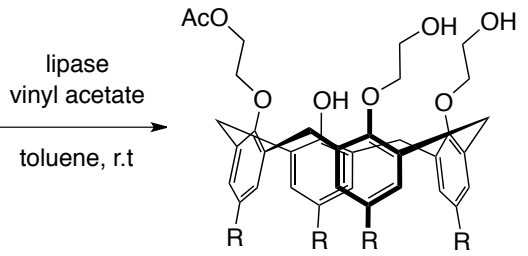

97b, $19 \%, 99 \%$ ee*

C. cylindracea lipase: $97 \mathrm{a}, 18 \%, \quad 0 \%$ ee
A. niger lipase: $97 \mathrm{a}, \quad 8 \%, 86 \% e e^{\star}$

Scheme 43. Inherently chiral calix[4]arenes via enzymatic desymmetrization. *Absolute configuration not determined, random enantiomer depicted. 


\section{Oxidoreductases as catalyst}

Redox chemistry represents a key player, and occasionally an unavoidable requirement, in the vast majority of synthetic strategies. Over the years, biocatalysis has proved be a highly interesting tool when it comes to oxidation and reduction chemistry. With numerous powerful and often very mild and selective enzymatic protocols nowadays on the market, contemporary biocatalysis is offering great benefit particularly in the field of redox transformations. ${ }^{97,98}$ Surprisingly, until now the enzyme chemistry of non-centrochiral organic and organometallic molecules is almost exclusively based on the long-known, but also highly efficient systems of alcohol dehydrogenases. As a rather conserved motif found in bacteria, yeasts and higher organisms alike, zinc-dependent alcohol dehydrogenases generally rely on a ternary arrangement involving not only the alcohol substrate and the catalytic metalloprotein but also the indispensable nicotinamide cofactor $\left(\mathrm{NAD}^{+}\right.$or $\left.\mathrm{NADP}^{+}\right){ }^{99,100}$ In the oxidative pathway, alcohol
Tetrahedron

coordination to the zinc center brings the oxidizable substrate in close proximity to the cofactor pyridinium unit allowing for the formation of the corresponding carbonyl compound via a proton relay and subsequent hydride transfer from the zinc alkoxide (Scheme 44). ${ }^{101}$ Depending on the reaction conditions, both alcohol oxidation and carbonyl reduction can be performed by the same enzyme making this class of biocatalysts a highly flexible synthetic tool. With the nicotinamide derivatives as hydride acceptor/donor reagent, preparative methods based on isolated dehydrogenases require the recycling of the very costly, desired cofactor $\left(\mathrm{NAD}(\mathrm{P})^{+}\right.$for oxidations, $\mathrm{NAD}(\mathrm{P}) \mathrm{H}$ for reductions), ${ }^{102}$ an effort that can be avoided by use of whole cell systems. In any case, both isolated proteins and whole cell approaches have found many applications in the past decades and provided novel steeoselective routes towards axially and planar chiral building blocks.
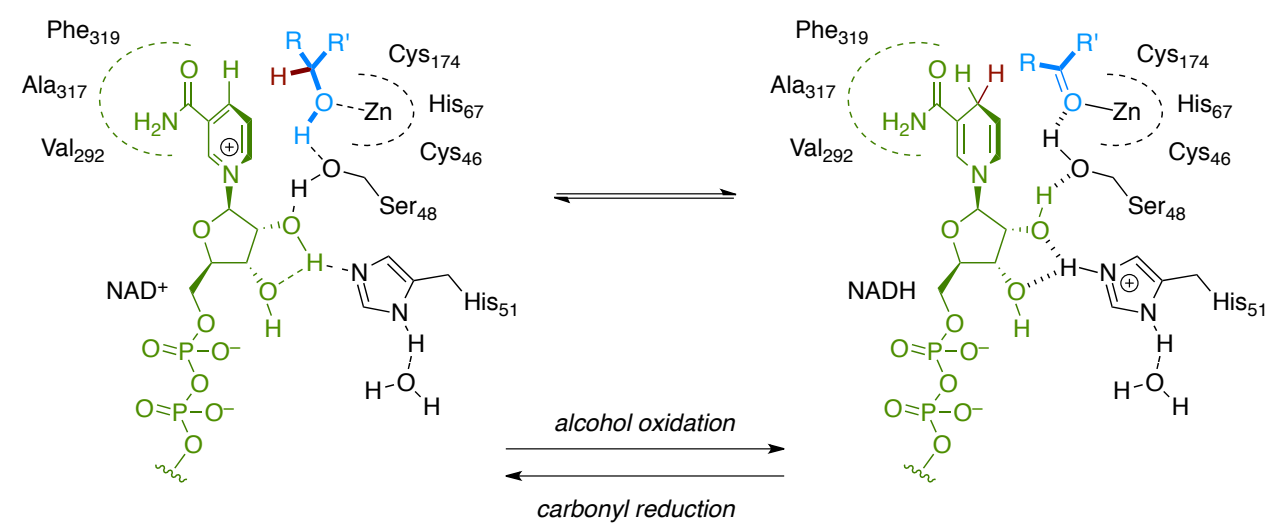

Scheme 44. Simplified active site arrangement of cofactor- (green) and substrate-bound (blue) alcohol dehydrogenase (here: ADH from horse liver) 


\subsection{Axial chirality}

In an early example of an oxidoreductase-based protocol for the preparation of enantioenriched axially chiral compounds, Gil et al. investigated the microbial oxidation of various allenols by a bacterial strain from Pseudomonas aeruginosa (ATCC 17504). ${ }^{103,104}$ Both alcohol and aldehyde dehydrogenase activity were detected and in a kinetic resolution, optically active allenol (S)-98 could be re-isolated after extensive oxidation, with the allenic carboxylic acid 99 as major fermentation product (Scheme 45).

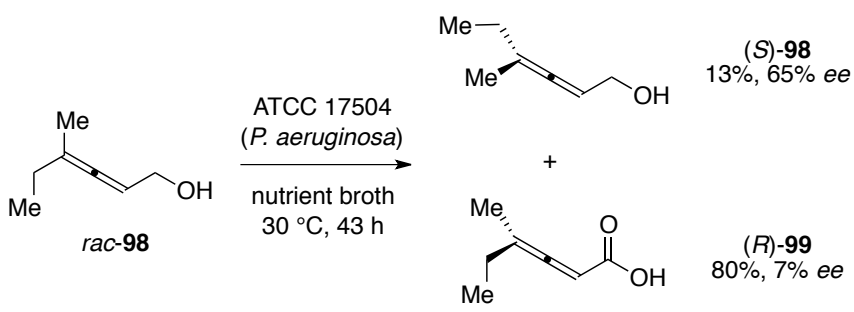

Scheme 45. Microbial enantioselective dehydrogenation of allenic alcohols.

In 1988, Miyano and coworkers chose baker's yeast as whole cell biocatalytic system for the selective transformation of binaphthyl-2-carbaldehydes. ${ }^{105}$ Under reductive conditions, the (S)-configured non-symmetric 2'-substituted 2-formylbinaphthyls were preferentially converted to the corresponding atropisomeric alcohols with moderate enantioselectivity $\left(k_{\text {rel }} 6.6\right.$ - 8.7) (Scheme $46)$. For the non-2'-substituted aldehyde, on the other hand, inverted enantiopreference in favor of the $(R)$-alcohol was detected, however, at a very low level of selectivity $\left(k_{\mathrm{rel}}=1.5\right)$.

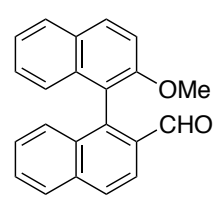

rac-100
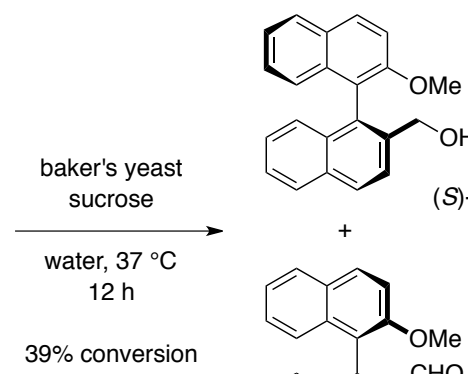

(S)-101, 70\% ee<smiles>COc1ccc2ccccc2c1-c1c(C=O)ccc2ccccc12</smiles>

(R)-100, ee n.d.

Scheme 46. Reductive kinetic resolution of non- $C_{2}$-symmetric binaphthyl carbaldehydes.

Atropisomeric diaryl ethers, that are for example found as substructure in the antibiotic vancomycin, have been targets of a joined study by the groups of Clayden and Turner. ${ }^{106,107}$ From a commercial set of alcohol dehydrogenases, two complementary enzymes were identified to catalyze the stereoselective reduction of 2,6-diformyl-decorated diphenyl ethers such as $\mathbf{1 0 2}$ with high activity to yield axially chiral monoformyl diaryl ethers (Scheme 47). In combination with glucose/glucose dehydrogenase as NADPH-recycling system, the enzymes KRED118 and KRED121 provided moderate optical purities for the desired products both in the $(S)$ - and $(R)$-series, respectively.

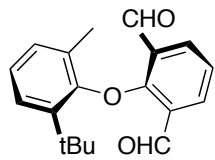

102

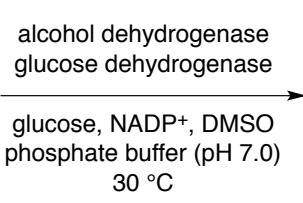
$30{ }^{\circ} \mathrm{C}$

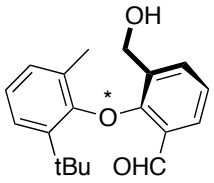

$(S)$ - or $(R)-103$ alcohol dehydrogenase $=$ KRED $118: 91 \%, 77 \%$ ee $(S)$ KRED121: $84 \%, 61 \%$ ee $(R)$

Scheme 47. Formation of atropisomeric diaryl ethers via reductive desymmetrization. KRED118/121 = ADHs from Codexis screening kit.

As part of the same study, ${ }^{106,107}$ an alternative biocatalytic system was employed to generate the axially chiral ethers though an oxidative pathway. Providing good activity in the aerobic dehydrogenation of certain primary alcohols, ${ }^{108}$ the $\mathrm{M}_{3-5}$ variant of galactose oxidase proved to be more selective than its reductive counterparts giving rise to a series of highly enantioenriched aldehyde-functionalized diaryl ethers via oxidative desymmetrization of the corresponding 2,6dimethanols (e.g. 104, Scheme 48).

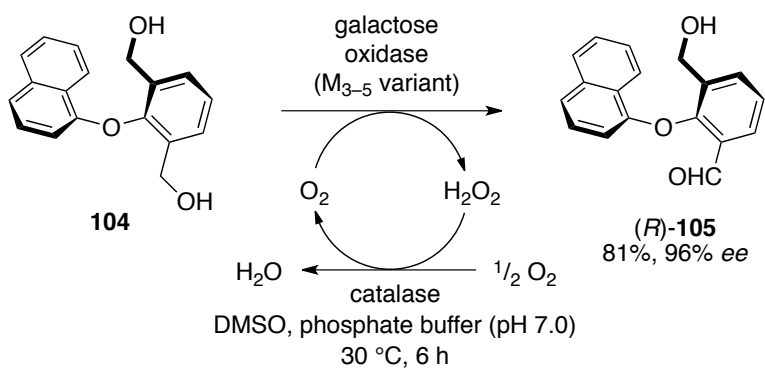

Scheme 48. Oxidase-catalyzed enantioselective dehydrogenation.

In 2012, Reetz and coworkers investigated a rather overlooked structural entity featuring axial chirality. In a very broad screening, numerous commercial alcohol dehydrogenases were tested for their ability for the enantioselective reduction of 4alkylidenecyclohexanones (106). ${ }^{109}$ Here, an entire set of enzymes provided good activity and selectivity for the synthesis of axially chiral alkylidenecyclohexanols giving rise to either $(S)$ or $(R)$-configured alcohols $\mathbf{1 0 7}$ in moderate to excellent optical purity (Scheme 49). Furthermore, directed evolution of the alcohol dehydrogenase of Thermoethanolicus brockii led to improved biocatalysts for the title reaction but also for the stereoselective reduction of corresponding four- and eightmembered alkylidenecycloalkanones. 


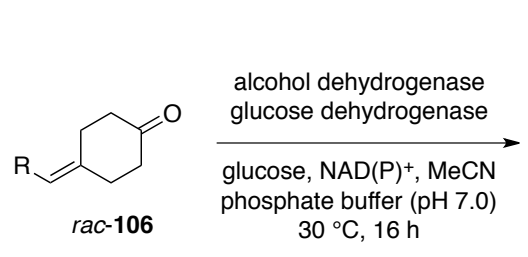

a) $\mathrm{ADH}=\mathrm{A} 13$; b) $\mathrm{ADH}=\mathrm{A} 32$

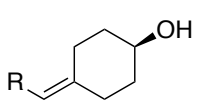

(S)-107

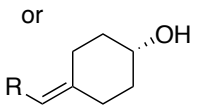

(R)-107

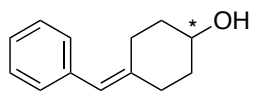

a): (R)-107a, 97\%, 98\% ee b): (S)-107a, 99\%, 96\% ee

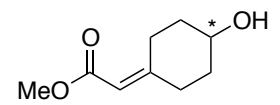

a): $(R)-107 c, 99 \%, 95 \%$ ee
b): $(S)-107 c, 99 \%, 59 \%$ ee<smiles>OC1CCC(=CBr)CC1</smiles>

a): (R)-107b, 99\%, 95\% ee b): (S)-107b, 99\%, $81 \%$ ee<smiles>CC=C1CCC(O)CC1</smiles>

a): $(R)-107 d, 99 \%, 67 \%$ ee b): (S)-107d, 99\%, 42\% ee

Scheme 49. Synthesis of axially chiral alkylidenecyclohexanols via asymmetric reduction. A13/A32 = ADHs from X-zymes screening kit.

An even greater challenge than stereoselective functional group manipulations represents the direct construction of axial chirality by $C$ - $C$-coupling reactions. Although oxidizing enzymes such as laccases, peroxidases and cytochrome monooxygenases are well known to catalyze the oxidative biaryl coupling between activated arenes such as phenols, it was long believed that the atroposelective synthesis via phenol dimerization could not be achieved due to the free radical character of these transformations. In 2015, Wang, Schaller and coworkers reported on the identification and usage of dirigent proteins from cotton (Gossypium sp.) that allowed for the sterecontrolled synthesis of the axially chiral gossypol (109) (Scheme 50). ${ }^{110}$ While the oxidative dimerization of $\mathbf{1 0 8}$ by laccase from Trametes versicolor proceeded in an entirely racemic fashion, in presence of a dirigent protein (GhDIR4 from Gossypium hirsutum) in addition to the fungal laccase one-electron oxidizer $(S)-(+)-$ gossypol (109) was formed in up to $80 \%$ ee.

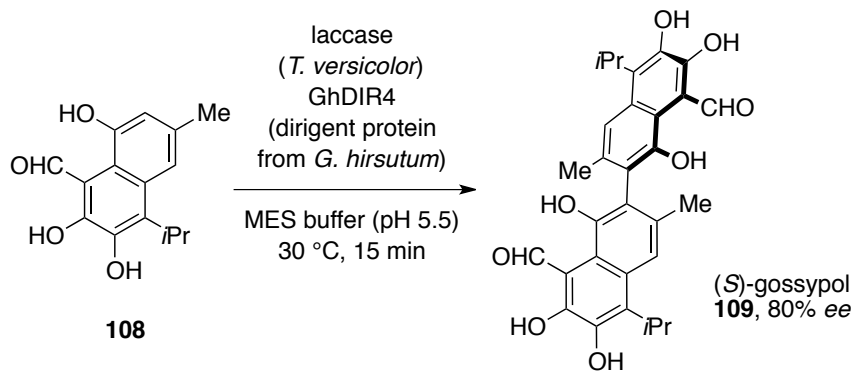

Scheme 50. Atroposelective synthesis of gossypol through enzymatic oxidative phenol coupling

Most recently, Müller et al. discovered two truely atroposelective monooxygenases that proved to be effective in the oxidative dimerization of 7-demethylsiderin $(\boldsymbol{\epsilon}))^{111}$ In an insilico approach, specific phenol coupling enzymes were identified in Aspergillus niger $(\mathrm{KtnC})^{112}$ and Emericella desertorum (DesC) and successfully expressed in baker's yeast.

Fermentation of 7-demethylsiderin in the $\mathrm{KtnC}$-modified yeast resulted in the formation of $(S)$-orlandin (111, 8, $8^{\prime}$-dimer) while the DesC-containing organism selectively produced the $6,8^{\prime}-$ regioisomer $(R)$-desertorin A (112)(Scheme 51).

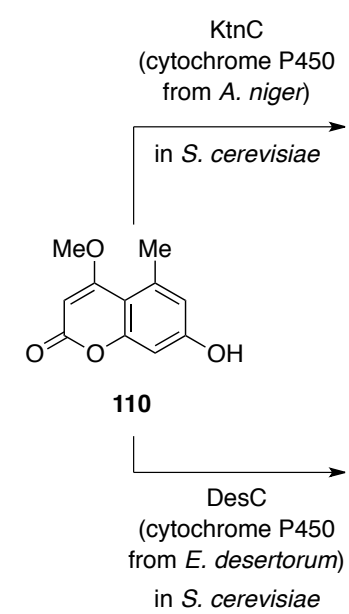

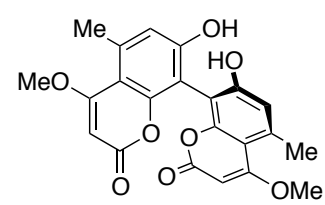

(S)-orlandin, 111

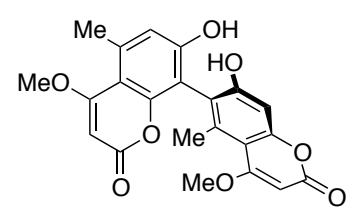

(R)-desertorin A, 112

Scheme 51. Regio- and stereoselective biaryl coupling via cytochrome-mediated oxidative 7-demethylsiderin dimerization. 


\subsection{Planar chirality}

In 1988, Maiorana et al. introduced organometallic sandwich structures as substrates also for fermentative stereoselective reductions based on the baker's yeast platform. As shown for a number of $\left(\eta^{6}\right.$-benzaldehyde)chromium tricarbonyls ( $\left.r a c-113\right)$, the responsible $S$. cervisae alcohol dehydrogenase catalyzed the kinetic resolution with high rates and moderate to good enantiodiscrimination. allowing for the preparation of the planar chiral 1,2-disubstituted chromium complexes in optical purities up to $96 \%$ ee (Scheme 52). ${ }^{113,114}$ 1,3-Disubstituted arenechromium complexes were also included, however, did not yield high enantiomeric excesses.

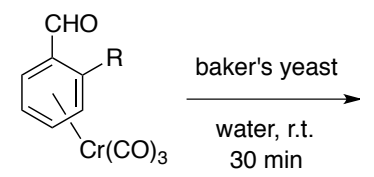

rac-113

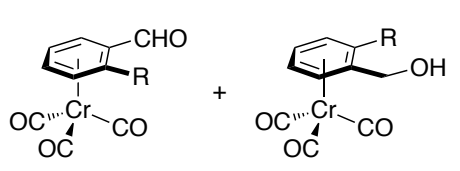

$(S)$ - or $(R)-\mathbf{1 1 3}$

$(R)$ - or $(S)-114$

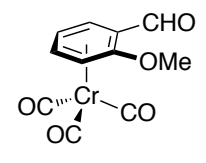
$(S)-113 a$
$45 \%, 81 \%$ ee

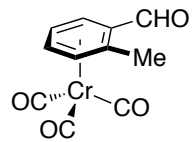

$(R)-113 b$ $41 \%, 96 \%$ ee

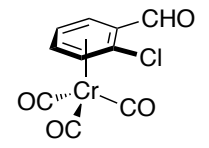
$(S)-113 c$
$30 \%, 87 \%$ ee<smiles>O=CC1=C(F)[Ge](C(O)(C=O)C=O)C=C1</smiles>

$(S)-113 d$
$27 \%, 52 \%$

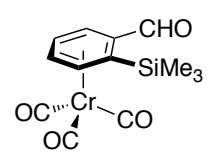

$(S)-113 e$
$26 \%, 75 \%$
Scheme 52. Baker's yeast as catalyst in the kinetic resolution of a 2-methoxybenzaldehyde chromium tricarbonyl complex.

Soon after Maiorana's initial studies, various half- and fullsandwich organometallics have been considered as targets in biocatalytic redox transformations. Yamazaki and coworkers reported on a broad screening of fungal and bacterial strains in search for stereoselective reduction catalysts. On one side, the excellent result of Maiorana on the reductive resolution of 113b could be even surpassed by bioreduction through a Nocardia erythropolis strain (IAM 12122) yielding the remaining aldehyde in enantiomerically pure form. ${ }^{115}$ Moreover, decorated cyclopentadienyl complexes of iron and manganese were included and Candida boidinii (IAM 12269) provided high stereoselectivities in the kinetic resolution of manganese tricarbonyl complexes giving rise to nearly enantiopure $(R)-\mathbf{1 1 5}$ (Scheme 53).

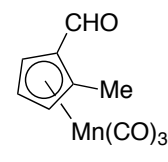

rac-115

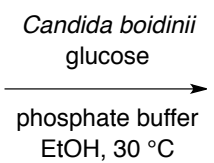

$2 \mathrm{~h}$

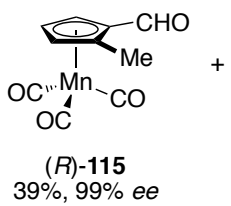

$(R)-115$
$39 \%, 99 \%$ ee

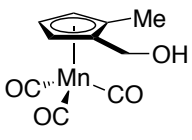

(S) -116 $49 \%, 44 \%$ ee

Scheme 53. Fermentative resolution of planar chiral manganese tricarbonyls by Candida boidinii.

The group of Izumi investigated propylene-bridged [3] $\left(1,1^{\prime}\right)$ ferrocenophanes as co-substrates in baker's yeast fermentations as an extension of the non-bridged 1,2- and 1,3-

disubstituted manganese- and iron-cyclopentadienyl complexes. Ferrocenophanes with both proximal (117) and distal formyl groups (118) relative to the propylene linker were well accepted by the yeast's dehydrogenase, however, for either system optical purities of the resolved compounds remained only moderate. (Scheme 54).

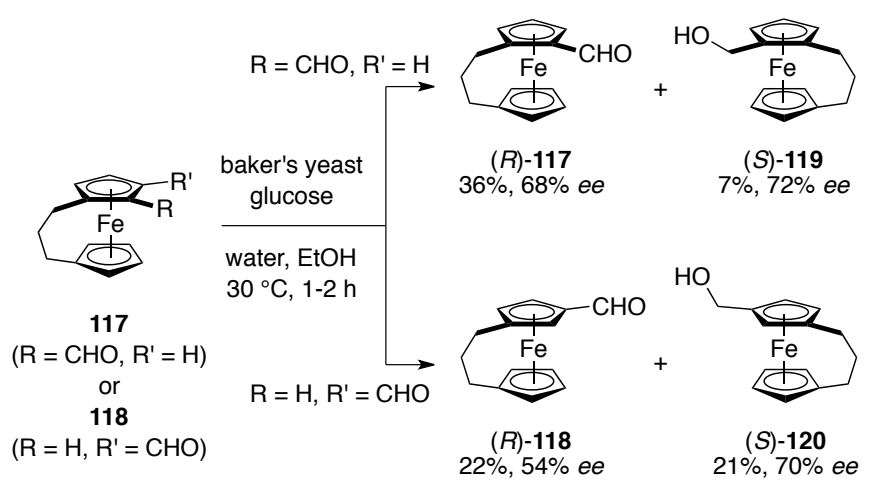

Scheme 54. Ferrocenophanes as substrates of yeast alcohol dehydrogenase-catalyzed resolutions.

In addition to enzymatic kinetic resolutions based on yeast dehydrogenase-catalyzed reductions, the groups of Yamazaki $^{116,117}$ and Izuma $^{15,118}$ also reported on both oxidoreductase-mediated desymmetrizations of ferrocenes.' Exploiting isolated horse liver alcohol dehydrogenase, ${ }^{116}$ the right choice of cofactor recycling systems allowed for both oxidative and reductive transformations of symmetrically difunctionalized iron complexes (Scheme 55). In combination with glutamate dehydrogenase and 2-oxoglutarate as terminal oxidant, dehydrogenation of $\mathbf{1 2 1}$ delivered the planar chiral $(S)-\mathbf{1 2 2}$ in high yield and $86 \%$ enantiomeric excess. An even higher optical purity was achieved und reductive conditions by transfer hydrogenation from ethanol to $\mathbf{1 2 3}$ furnishing the enantiomeric $(R)-\mathbf{1 2 2}$ in $94 \%$ ee.

oxidative desymmetrization

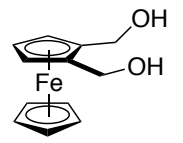

121

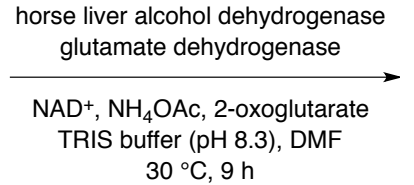

$30{ }^{\circ} \mathrm{C}, 9 \mathrm{~h}$

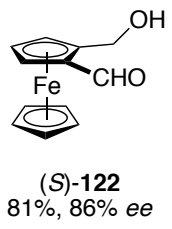

$81 \%, 86 \%$ ee reductive desymmetrization

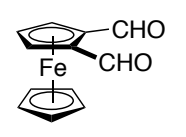

123

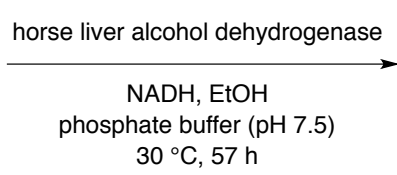

$30{ }^{\circ} \mathrm{C}, 57 \mathrm{~h}$

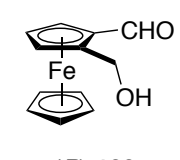

$(R)-122$
Scheme 55. Oxidative and reductive desymmetrization of ferrocenes by horse liver alcohol dehydrogenase.

Yamazaki's early ferrocene studies also included a survey on non-dehydrogenase biocatalysts as potential stereoselective mediators. Here, out of a set of 144 microorganisms two bacterial monooxygenases - from Corynebacterium equi IFO 3730 and Arthrobacter simplex IAM 1660 - were identified as effective oxidation catalysts recognizing planar prochirality in the organometallic bis-sulfide $124 .^{119}$ For both strains, excellent 
enantiodiscrimination was observed and the latter produced the mono-sulfoxide $(S)-\mathbf{1 2 5}$ as major product in high yield (Scheme 56). Interestingly, in both cases only moderate selectivity for the formation of the chirogenic sulfoxide center was detected and the products were isolated as mixtures of diastereomers $(\mathrm{dr}=4: 1)$ with identical sense of planar chirality.

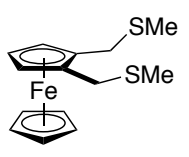

124

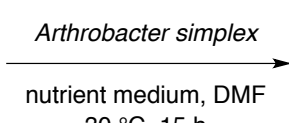

$30{ }^{\circ} \mathrm{C}, 15 \mathrm{~h}$

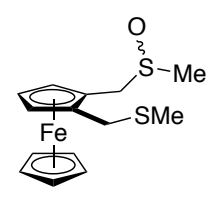

$(S)-125$
$87 \%, 99 \%$ ee, $d r=4: 1$

Scheme 56. Monooxygenase-catalyzed desymmetrization via sulfide-to-sulfoxide oxidation.

Extending the substrate portfolio of baker's yeast to nonaromatic $\left(\eta^{4}\right.$-diene)iron complexes, Howell et al. successfully desymmetrized 1,4-diformylbutadiene iron tricarbonyl in an enantioselective fashion. Bioreduction of $\mathbf{1 2 6}$ proceeded with good enantiotopos differentiation and gave rise to the planar chiral primary alcohol $(R)-\mathbf{1 2 7}$ as major product in $90 \%$ ee (Scheme 57). ${ }^{90,120}$

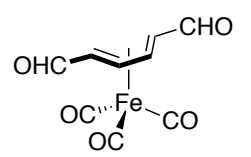

126

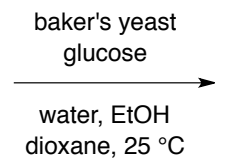

dioxane, $25^{\circ} \mathrm{C}$

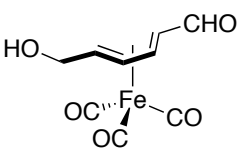

(R)-127, $80 \%, 90 \%$ ee

Scheme 57. Synthesis of planar chiral iron tricarbonyl 121 through yeast-mediated bioreduction.

In 1997, Pietzsch and coworkers demonstrated that also [2.2]paracyclophanes can be used as substrates in bioreductions performed by baker's yeast. ${ }^{121}$ Following up on a preliminary study by Izumi and Hinata, ${ }^{92}$ ten different microorganisms as well as isolated alcohol dehydrogenases were evaluated as biological catalysts for the selective reduction of 2-formyl[2.2]paracyclophane (128) and while all microbial whole cell systems provided activity, a baker's yeast strain $(S$. cerevisiae DSM 11285) was identified as most enantioselective reducing agent. Hence, after co-fermentation of $\mathrm{rac} \mathbf{- 1 2 8}$ the planar chiral aldehyde was re-isolated in excellent optical purity (Scheme 58).

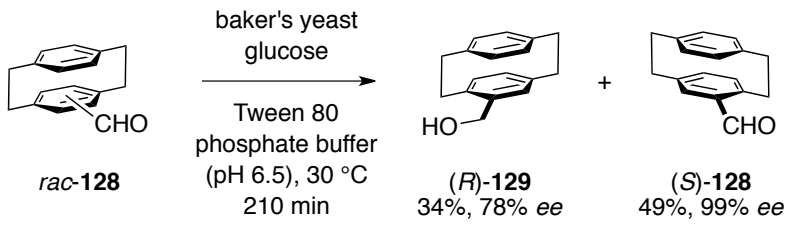

Scheme 58. Baker's yeast as catalyst in the kinetic resolution of a 2-methoxybenzaldehyde chromium complex. 


\section{Micellaneous biocatalytic systems}

Occasionally, also other natural catalyst systems come into play, although until now, only in a very few examples targeting axial chirality have been reported. As early as 1975, Miesowicz and Bloch described the isolation of an isomerase from hog liver that was able - in addition to the cis/trans-isomerisation of enoyl$\mathrm{CoA}$ derivatives - to perform the formal prototropic rearrangement of 3-decynoic acid thioesters to yield optically active, axially chiral allenoates, as judged from their specific rotation. ${ }^{122}$ Good yields were obtained with the $\mathrm{N}$ acetylcysteamin thioester $\mathbf{1 3 0}$ (Scheme 59), but also pantetheineand coenzyme-A-derived substrates were converted at reasonable rates, however, the degree of enantioenrichment was not explicitely determined.

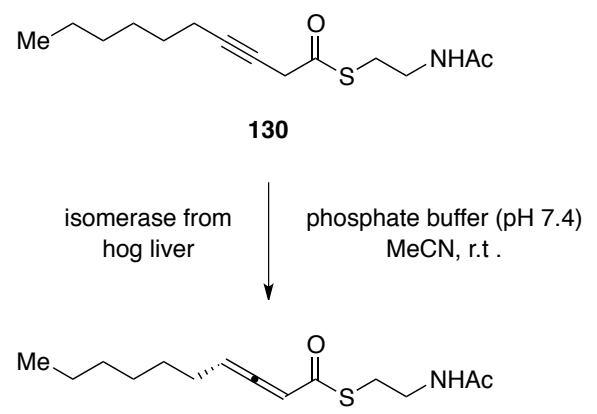

(S)-131, 71\%, ee not determined

Scheme 59. Formation of allenic thioester 131 through isomerase-mediated prototropic rearrangement.

Prior to Zemlicka's investigations on the lipase-mediated resolution of allenic nucleoside mimics (vide supra), ${ }^{35}$ the group studied a number of enzymes acting on adenallene (132) and adenallene 4'-phosphate with regard to the potential metabolic behavior of the anti-HIV active compounds as well as stereochemical aspects of these processes. Dephosphorylation of the corresponding adenallene 4'-phosphate with 5'-nucleosidase or alkaline phosphatase turned out rather unselective with optical purities of the resulting compounds of $\leq 54 \% e e .^{123,124}$ Similarly, deamination of the racemic phosphate by AMP deaminase yielded hypoxallene 4'-phosphate in completely racemic fashion. In contrast, the non-phosphorylated $\mathbf{1 3 2}$ was well recognized by bovine adenosine deaminase and both the hypoxallene product 133 as well as the starting material were isolated in good yields and excellent enantiopurity after hydrolytic kinetic resolution (Scheme 60). ${ }^{125}$
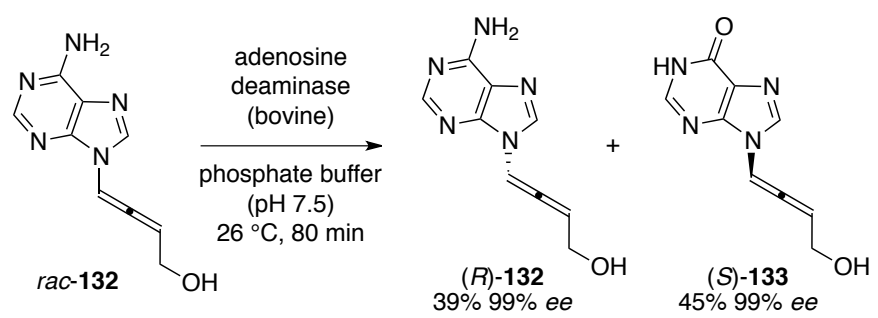

Scheme 60. Deaminative kinetic resolution of the anti-HIV nucleoside mimic adenallene.
In 2014, Wang and coworkers described the whole cell transformation of allenic nitriles in a biphasic reaction mixture by means of a Rhodococcus erythropolis AJ270 strain. The biotransformation combines the formation of the corresponding amides through a nitrile hydratase followed by amidase-mediated hydrolysis. While the lyase-catalyzed hydration was assumed to proceed without substantial enantiodiscrimination, kinetic resolution is taking place on the second step leading to the formation of $(R)$-configured allenic amides alongside with $(S)$ carboxylic acids (Scheme 61). For phenyl-substituted allenes (134a and 134b) good optical purities are obtained, however, only mediocre selectivity was observed for substrates bearing non-aromatic terminal substituents. ${ }^{126}$

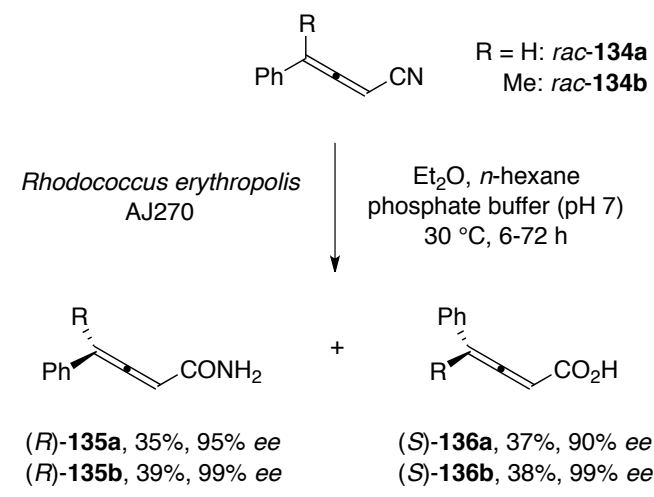

Scheme 61. Resolution of allenic nitriles based on a hydratase/amidase cascade.

\section{Summary}

During the past four decades, a wide variety of non-natural substrate structures featuring non-centrochiral stereogenic elements proved to be well recognized by natural catalysts underlining the power of enzymatic catalysis. Form the early attempts to simply create structurally challenging optically active compounds the development led to the most recent reports on the direct biocatalytic generation of pharmaceutically relevant molecules or the preparation of enantiopure building blocks that served as key intermediates in complex synthetic strategies. Considering the current wave of novel and highly efficient biocatalytic systems and the latest advances in enzyme design and optimization techniques, it appears safe to assume that the chase for new substrate structures will bring up new solutions and new applications also in the field of axial and planar chirality. 


\section{Acknowledgments}

We gratefully acknowledge financial support by the Fonds der Chemischen Industrie (Liebig fellowship for JD \& ChemiefondsStipendium for BS), the Deutsche Forschungsgemeinschaft (DE1599/4-1) and the Dr.-Otto-Röhm-Gedächtnisstiftung.

\section{References and notes}

1 Bringmann, G.; Price Mortimer, A. J.; Keller, P. A.; Gresser, M. J.; Garner, J.; Breuning, M. Angew. Chem. Int. Ed. 2005, 44, 5384-5427; Angew. Chem. 2012, 124, 3128-3167.

2 Feringa, B. L.; van Delden, R. A.; Koumura, N.; Geertsmaa, E. M. Chem. Rev. 2000, 100, 1789-1816.

3 Kitagawa, O.; Izawa, H.; Sato, K.; Dobashi, A.; Taguchi, T. J. Org. Chem. 1998, 63, 2634-2640.

$4 \quad$ Yu, S.; Ma, S. Angew. Chem. Int. Ed. 2012, 51, 30743112; Angew. Chem. 2012, 124, 3128-3167.

5 Gibson, S. E.; Knight, J. D. Org. Biomol. Chem. 2003, 1, 1256-1269.

6 Marquarding, D.; Klusacek, H.; Gokel, G.; Hoffmann, P.; Ugi, I. J. Am. Chem. Soc. 1970, 92, 5389-5393.

7 McIldowie, M. J.; Mocerino, M.; Ogden, M. I. Supramol. Chem. 2010, 22, 13-39.

8 Hoffmann-Röder, A.; Krause, N. Angew. Chem. Int. Ed. 2004, 43, 1196-1216; Angew. Chem. 2004, 116, 12161236.

9 Bringmann, G.; Gulder, T.; Gulder, T. A. M.; Breuning, M. Chem. Rev. 2011, 111, 563-639.

10 Clayden, J.; Moran, W. J.; Edwards, P. J.; LaPlante, S. R. Angew. Chem. Int. Ed. 2009, 48, 6398-6401; Angew. Chem. 2009, 121, 6516-6520.

11 Smith, D. E.; Marquez, I.; Lokensgard, M. E.; Rheingold, A. L.; Hecht, D. A.; Gustafson, J. L. Angew. Chem. Int. Ed. 2015, 54, doi:10.1002/anie.201506085.

12 Noyori, R.; Takaya, H. Acc. Chem. Res. 1990, 23, 345350 .

13 Tang, W.; Zhang,X. Chem. Rev. 2003, 103, 3029-3069.

14 Blaser, H.-U.; Brieden, W.; Pugin, B.; Spindler, F.; Studer, M.; Togni, A. Top. Catal. 2002, 19, 3-16.

15 Blaser, H.-U.; Pugin, B.; Spindler, F.; Thommen, M. Acc. Chem. Res. 2007, 40, 1240-1250.

16 Parmar, D.; Sugiono, E.; Raja, S.; Rueping, M. Chem. Rev. 2014, 114, 9047-9153.

17 Maruoka, K.; Ooi, T. Chem. Rev. 2003, 103, 3013-3028.

18 Müller, C. E.; Schreiner, P. R. Angew. Chem. Int. Ed. 2011, 50, 6012-6042; Angew. Chem. 2011, 123, 61366167.
19 Faber, K. Biotransformations in Organic Chemistry, 5th ed., Springer, Berlin, 2008.

20 V. Gotor, I. Alfonso, E. García-Urdiales, Asymmetric Organic Synthesis with Enzymes, 1st ed.., Wiley-VCH, Weinheim, 2008.

21 Ogasawara, M. Tetrahedron: Asymmetry 2009, 20, 259271.

22 Yu, S.; Ma, S. Chem. Commun. 2011, 47, 5384-5418.

23 Ma, G.; Sibi, M. P. Chem. Eur. J. 2015, 21, 1164411657.

24 Bornscheuer, U. T.; Kazlauskas, R. J. in Hydrolases in Organic Synthesis: Regio- and Stereoselective Biotransformations, 2nd ed., Wiley-VCH, Weinheim, 2005.

25 Uppenberg, J.; Öhrner, N.; Norin, M.; Hult, K.; Kleywegt, G. J.; Patkar, S.; Waagen, V.; Anthonsen, T.; Jones, T. A. Biochemistry 1995, 34, 16838-16851.

26 Naemura, K.; Furutani, A., J. Chem. Soc., Perkin Trans. 1 1990, 3215-3217.

27 Naemura, K.; Furutani, A., J. Chem. Soc., Perkin Trans. 1 1991, 2891-2892.

28 Matsushima, Y.; Kitahara, T.; Mori, K. Biosci. Biotechnol. Biochem. 1998, 62, 1435-1437.

29 Ramaswamy, S.; Hui, R. A. H. F.; Jones, J. B., J. Chem. Soc., Chem. Commun. 1986, 1545-1543.

30 Pietzsch, M.; Vielhauer, O.; Pamperin, D.; Ohse, B.; Hopf, H., J. Mol. Catal. B Enzym. 1999, 6, 51-57.

31 Carballeira, J. D.; Krumlinde, P.; Bocola, M.; Vogel, A.; Reetz, M. T.; Bäckvall, J.-E., Chem Commun. 2007, 1913-1915.

32 Reetz, M. T.; Bocola, M.; Carballeira, J. D.; Zha, D.; Vogel, A. Angew. Chem. Int. Ed. 2005, 44, 4192-4196; Angew. Chem. 2005, 117, 4264-4268.

33 Gil, G.; Ferre, E.; Meou, A.; Le Petit, J.; Triantaphylides, C. Tetrahedron Lett. 1987, 28, 1647-1648.

34 Cipiciani, A.; Belezza, F. J. Mol. Catal. B: Enzym. 2002, 17, 261-266.

35 Jones, B. C. N. M.; Silverton, J. V.; Simons, C.; Megati, S.; Nishimura, H.; Maeda, Y.; Mitsuya, H.; Zemlicka, J. J. Med. Chem. 1995, 38, 1397-1405.

36 Deska, J.; Bäckvall, J.-E., Org. Biomol. Chem. 2009, 7, 3379-3381.

37 Horváth, A.; Bäckvall, J.-E., Chem. Commun. 2004, 964965.

38 Deska, J.; del Pozo Ochoa, C.; Bäckvall, J.-E., Chem. Eur. J. 2010, 16, 4447-4451.

39 Manzuna Sapu, C.; Bäckvall, J.-E.; Deska, J, Angew. Chem. Int. Ed. 2011, 50, 9731-9734; Angew. Chem. 2011, 123, 9905-9905. 
40 Manzuna Sapu, C.; Deska, J. Org. Biomol. Chem. 2013, 11, 1376-1382.

41 Hammel, M.; Deska. J. Synthesis 2012, 44, 3789-3796.

42 Fiaud, J.-C.; Gil, R.; Legros, J.-Y.; Aribi-Zouioueche, L.; König, W. A. Tetrahedron Lett. 1992, 33, 6967-6970.

43 Fujimoto, Y.; Iwadate, H.; Ikekawa, N. J. Chem. Soc., Chem. Commun. 1985, 1333-1334.

44 Kazlauskas, R. J. J. Am. Chem. Soc. 1989, 111, 49534959.

45 Kazlauskas, R. J. Org. Synth. 1992, 70, 60.

46 Blakemore, P. R.; Milicevic, S. D.; Zakharov, L. N. J. Org. Chem. 2007, 72, 9368-9371.

47 Miyano, S.; Kawahara, K.; Inoue, Y.; Hashimoto, H. Chem. Lett. 1987, 16, 355-356.

48 Lin, G.; Chen, S.-J.; Sun, H.-L. J. Chin. Chem. Soc. 1994, 41, 459-465.

49 Birner-Grünberger, R.; Scholze, H.; Faber, K.; Hermetter, A. Biotechnol. Bioeng. 2004, 85, 147-154.

50 Inagaki, M.; Hiratake, J.; Nishioka, T.; Oda, J. Agric. Biol. Chem. 1989, 53, 1879-1889.

51 Juárez-Hernandez, M.; Johnson, D. V.; Holland, H. L.; McNulty, J.; Capretta, A. Tetrahedron: Asymmetry 2003, 14, 289-291.

52 Sanfilippo, C.; Nicolosi, G.; Delugo, G.; Fabbri, D.; Dettori, M. A. Tetrahedron: Asymmetry 2003, 14, 3267 3270 .

53 Furutani, T.; Hatsuda, M.; Imashiro, R.; Seki, M. Tetrahedron: Asymmetry 1999, 10, 4763-4768.

54 Sanfilippo, C.; D'Antona, N.; Nicolosi, G. Tetrahedron: Asymmetry 2006, 17, 12-14.

55 Seki, M.; Furutani, T.; Hatsuda, M.; Imashiro, R. Tetrahedron Lett. 2000, 41, 2149-2152.

56 Yang, D.; Yip, Y.-C.; Tang, M.-W.; Wong, M.-K.; Zheng, J.-H.; Cheung, K.-K. J. Am. Chem. Soc. 1996, 118, 491-492.

57 Tanaka, K.; Furuta, T.; Fuji, K.; Miwa, Y.; Taga, T. Tetrahedron: Asymmetry 1996, 7, 2199-2202.

58 Sanfilippo, C.; Nicolosi, G.; Delogu, G.; Fabbri, D.; Dettori, M. A. Tetrahedron: Asymmetry 2005, 16, 1079 1084.

59 Aoyagi, N.; Kawauchi, S.; Izumi, T. Tetrahedron Lett. 2003, 44, 5609-5612.

60 Taniguchi, T.; Fukuba, T.-A.; Nakatsuka, S.; Hayase, S.; Kawatsura, M.; Uno, H.; Itoh, T. J. Org. Chem. 2008, 73, 3875-3884.

61 Aoyagi, N.; Izumi, T. Tetrahedron Lett. 2002, 43, 55295531.
62 Aoyagi, N.; Ohwada, T.; Izumi, T. Tetrahedron Lett. 2003, 44, 8269-8272.

63 Aoyagi, N.; Kawauchi, S.; Izumi, T. Tetrahedron Lett. 2004, 45, 5189-5192.

64 Bringmann, G.; Price Mortimer, A. J.; Keller, P. A.; Gresser, M. J.; Garner, J.; Breuning, M. Angew. Chem. Int. Ed. 2005, 44, 5384-5427; Angew. Chem. 2005, 117, 518-5563.

65 Skrobo, B.; Deska, J. Tetrahedron: Asymmetry 2013, 24, 1052-1056.

66 Matsumoto, T.; Konegawa, T.; Nakamura, T.; Suzuki, K. Synlett 2002, 122-124.

67 Feringa, B. L.; van Delden, R. A.; Koumura, N.; Geertsema, E. M. Chem. Rev. 2000, 100, 1789-1816.

68 Morgan, B.; Zaks, A.; Dodds, D. R.; Liu, J.; Jain, R.; Megati, S.; Njoroge, F. G.; Girijavallabhan, V. M. J. Org. Chem. 2000, 65, 5451-5457.

69 Gingras, M.; Félix, G.; Peresutti, R. Chem. Soc. Rev. 2013, 42, 1007-1050.

70 Liu, L.; Katz, T. J. Tetrahedron Lett. 1990, 31, 39833986.

71 Tanaka, K.; Shogase, Y.; Osuga, H.; Suzuki, H.; Nakamura, K. Tetrahedron Lett. 1995, 36, 1675-1678.

72 Tanaka, K.; Osuga, H.; Suzuki, H.; Shogase, Y.; Kitahara, Y. J. Chem. Soc., Perkin Trans 1 1998, 935940.

73 Alba, A.-N. R.; Rios, R. Molecules 2009, 14, 4747-4757.

74 Schaarschmidt, D.; Lang, H. Organometallics 2013, 32, 5668-5704.

75 Yamazaki, Y.; Hosono, K. Ann. New York Acad. Sci. 1990, 613, 738-746.

76 Yamazaki, Y.; Morohashi, N.; Hosono, K. Biotechnol. Lett. 1991, 13, 81-86.

77 Malézieux, B.; Jaouen, G.; Salaün, J.; Howell, J. A. S.; Palin, M. G.; McArdle. P.; O'Gara, M.; Cunningham, D. Tetrahydro: Asymmetry 1992, 3, 375-376.

78 Izumi, T.; Tamura, F.; Sasaki, K. Bull. Chem. Soc. Jpn. 1992, 65, 2784-2788.

79 Izumi, T.; Aratani, S. J. Chem. Tech. Biotechol. 1994, 59, 403-408.

80 Izumi, T.; Aratani, S. J. Chem. Tech. Biotechnol. 1993, 57, 33-36.

81 Izumi, T.; Hino, T.; Ishihara, A. J. Chem. Tech. Biotechnol. 1993, 56, 45-49.

82 Nicolosi, G.; Patti, A.; Morrone, R.; Piattelli, M. Tetrahedron: Asymmetry 1994, 5, 1275-1280.

83 Lambusta, D.; Nicolosi, G.; Patti, A.; Piattelli, M. Tetrahedron Lett. 1996, 37, 127-130. 
84 Patti, A.; Lambusta, D.; Piattelli, M.; Nicolosi, G.; McArdle, P.; Cunningham, D.; Walsh, M. Tetrahedron 1997, 53, 1361-1368.

85 Patti, A.; Lambusta, D.; Piattelli, M.; Nicolosi, G. Tetrahedron: Asymmetry 1998, 9, 3073-3080.

86 Merabet-Khelassi, M.; Aribi-Zouioueche, L.; Riant, O. Tetrahedron: Asymmetry 2008, 19, 2378-2384.

87 Merabet-Khelassi, M.; Aribi-Zouioueche, L.; Riant, O. Tetrahedron: Asymmetry 2009, 20, 1371-1377.

88 Rigby, J. H.; Sugathapala, P. Tetrahedron Lett. 1996, 37, 5293-5296.

89 Alcock, N. W.; Crout, D. H. G.; Henderson, C. M.; Thomas, S. E. J. Chem. Soc., Chem. Commun. 1988, 746-747.

90 Howell, J. A. S.; Palin, M. G.; Jaouen, G.; Top, S.; El Hafa, H.; Cense, J. M. Tetrahedron: Asymmetry 1993, 4, 1241-1252.

91 Romanski, S.; Kraus, B.; Schatzschneider, U.; Neudörfl, J.-M.; Amslinger, S.; Schmalz, H.-G. Angew. Chem. Int. Ed. 2011, 50, 2392-2396.

92 Izumi, T.; Hinata, T. J. Chem. Tech. Biotechnol. 1992, $55,227-231$.

93 Braddock, D. C.; MacGilp, I. D.; Perry, B. G. J. Org. Chem. 2002, 67, 8679-8681.

94 Pamperin, D.; Ohse, B.; Hopf, H.; Pietzsch, M. J. Mol. Catal. B 1998, 5, 317-319.

95 Pamperin, D.; Schulz, C.; Hopf, H.; Syldatk, C.; Pietzsch, M. Eur. J. Org. Chem. 1998, 1441-1445.

96 Browne, J. K.; McKervey, M. A.; Pitarch, M.; Russell, J. A.; Millership, J. S. Tetrahedron Lett. 1998, 39, 17871790.

97 Hollmann, F.; Arends, I. W. C. E.; Buehler, K.; Schallmey, A.; Bühler, B. Green Chem. 2011, 13, 226265.

98 Hollmann, F.; Arends, I. W. C. E.; Holtmann. D. Green Chem. 2011, 13, 2285-2314.

99 Danielsson, O.; Jörnvall, H. Proc. Natl. Acad. Sci. 1992, 89, 9247-9251.

100 Leskovac, V.; Trivić, S.; Peričin, D. FEMS Yeast Res. 2002, 2, 481-494.

101 Agarwal, P. K.; Webb, S. P.; Hammes-Schiffer, S. J. Am. Chem. Soc. 2000, 122, 4803-4812.

102 van der Donk, W. A.; Zhao, H. Curr. Opin. Biotechnol. 2003, 14, 421-426.

103 Bertrand, M.; Ferre, E.; Gil, G.; Le Ferre, J.; Deveze, L. Tetrahedron Lett. 1980, 21, 1711-1714..

104 Ferre, E.; Gil, G.; Bertrand, M.; Le Petit, J. Appl. Microbiol. Biotechnol. 1985, 21, 258-266.
105 Kawahara, K.; Matsumoto, M.; Hashimoto, H.; Miyano, S. Chem. Lett. 1988, 1163-1164.

106 Yuan, B.; Page, A.; Worrall, C. P.; Escalettes, F.; Willies, S. C.; McDuall, J. J. W.; Turner, N. J.; Clayden, J. Angew. Chem. Int. Ed. 2010, 49, 7010-7013; Angew. Chem. 2010, 122, 7164-7167.

107 Staniland, S.; Yuan, B.; Giménez-Agulló, N.; Marcelli, T.; Willies, S. C.; Grainger, D. M.; Turner, N. J.; Clayden, J. Chem. Eur. J. 2014, 20, 13084-13088.

108 Turner, N. J. Chem. Rev. 2011, 111, 4073-4087.

109 Agudo, R.; Roiban, G.-D.; Reetz, M. T. J. Am. Chem. Soc. 2013, 135, 1665-1668.

110 Effenberger, I.; Zhang, B.; Li, L.; Wang, Q.; Liu, Y.; Klaiber, I.; Pfannstiel, J.; Wang, Q.; Schaller, A. Angew. Chem. Int. Ed. 2015, 54, 14660-14663; Angew. Chem. 2005, 127, 14870-14874.

111 Mazzaferro, L. S.; Hüttel, W.; Fries, A.; Müller, M. J. Am. Chem. Soc. 2015, 137, 12289-12295.

112 Girol, C. G.; Fisch, K. M.; Heinekamp, T.; Günther, S.; Hüttel, W.; Piel, J.; Brakhage, A. A.; Müller, M. Angew. Chem. Int. Ed. 2012, 51, 9788-9791; Angew. Chem. 2005, 124, 9926-9929.

113 Top, S.; Jaouen, G.; Gillois, J.; Baldoli, C.; Maiorana, S. J. Chem. Soc., Chem. Commun. 1988, 1284-1285.

114 Top, S.; Jaouen, G.; Baldoli, C.; Del Buttero, P.; Maiorana, S. J. Organomet. Chem. 1991, 413, 125-135.

115 Yamazaki, Y.; Hosono, K. Biotechnol. Lett. 1989, 11, 679-684.

116 Yamazaki, Y.; Hosono, K. Tetrahedron Lett. 1988, 29, 5769-5770.

117 Yamazaki, Y.; Uebayashi, M.; Hosono, K. Eur. J. Biochem. 1989, 184, 671-680.

118 Izumi, T.; Hino. T.; Kasahara, A. J. Chem. Tech. Biotechnol. 1991, 50, 571-573.

119 Yamazaki, Y.; Hosono, K. Agric. Biol. Chem. 1990, 54, 2183-2186.

120 Howell, J. A. S.; O'Leary, P. J.; Palin, M. G. Tetrahedron: Asymmetry 1996, 7, 307-315.

121 Pamperin, D.; Hopf, H.; Syldatk, C.; Pietzsch, M. Tetrahedron: Asymm. 1997, 8, 319-325.

122 Miesowicz, F. M.; Bloch, K. E. Biochem. Biophys. Res. Commun. 1975, 65, 331-335.

123 Jones, B. C. N. M.; Zemlicka, J. Bioorg. Med. Chem. Lett. 1995, 5, 1633-1636.

124 Phadtare, S.; Zemlicka, J. J. Am. Chem. Soc. 1989, 111, 5925-5931.

125 Megati, S.; Goren, Z.; Silverton, J. V.; Orlina, J.; Nishimura, H.; Shirasaki, T.; Mitsuya, H.; Zemlicka, J. J. Med. Chem. 1992, 35, 4098-4104. 
126 Ao, Y.-F.; Wang, D.-X.; Zhao, L.; Wang, M.-X. J. Org. Chem. 2014, 79, 3103-3110. 